This is an author produced version of a paper published in Best Practice \& Research- Clinical Obstetrics and Gynaecology. This paper has been peer-reviewed but does not include the final publisher proof-corrections or journal pagination.

Citation for the published paper:

Valentin, L.

"Imaging in gynecology"

Best Practice \& Research- Clinical Obstetrics and Gynaecology, 2006, Issue: Aug 9.

http://dx.doi.org/10.1016/j.bpobgyn.2006.06.001

Access to the published version may require journal subscription.

Published with permission from: Elsevier 


\section{Imaging in gynecology}

Lil Valentin, MD, $\mathrm{PhD}$

Department of Clinical Sciences Malmö

Lund University

Sweden

Short title: imaging in gynecology

Correspondence: Professor Lil Valentin, Department of Obstetrics and Gynecology, Malmö University Hospital, 20502 Malmö, Sweden

Telephone: +4640332094 Fax: +4640962600

Email: lil.valentin@med.lu.se 


\begin{abstract}
This chapter summarizes the diagnostic performance (sensitivity, specificity, positive and negative likelihood ratios) of ultrasound, computer tomography, and magnetic resonance imaging in the diagnosis of various gynecological diseases and tumors. Positron emission tomography is not discussed. Imaging in infertility, in the diagnosis of Mullerian duct anomalies and in gynecological oncology (staging of gynecological cancers, diagnosis of recurrence of gynecological cancer, diagnosis of trophoblastic tumors) is not dealt with.
\end{abstract}

Ultrasound is the first line imaging method for discrimination between viable intrauterine pregnancy, miscarriage and tubal pregnancy in women with bleeding and/or pain in early pregnancy, for discrimination between benign and malignant adnexal masses and for making a specific diagnosis in adnexal tumors (e.g., dermoid cyst, endometrioma, hemaorrhagic corpus luteum, ectetera), for diagnosing intracavitary uterine pathology in women with bleeding problems, and for confirming or refuting pelvic pathology in women with pelvic pain. Magnetic resonance imaging may have a role as a secondary test in the diagnosis of adenomyosis, 'deep endometriosis' (e.g., endometriosis in the rectovaginal septum or in the utero-sacral ligaments), and in the diagnosis of extremely rare types of ectopic pregnancy (e.g., in the spleen, liver or retroperitoneum).

Key words (MESH):Ultrasonography, Magnetic Resonance Imaging, Diagnostic Imaging, Pelvis, Gynecology 


\section{Introduction}

The basis for making a correct diagnosis in women with gynecological problems is anamnesis and clinical examination. To confirm or refute a diagnosis suspected on the basis of these, clinicians often add imaging methods. To the best of my knowledge there are no randomized trials that have tried to answer the question whether adding one or other imaging method to anamnesis and clinical examination eventually affects the health of the patient, or has other effects, e.g., on the rate of correct diagnosis before institution of treatment or on the time taken to arrive at a correct diagnosis. The lack of randomized trials is probably explained either by it being obvious that adding imaging to clinical examination has positive effects, or by difficulties with conducting a randomized trial, e.g., because of difficulties with defining relevant outcome measures or difficulties caused by the need for life-long follow-up. On the other hand, clinical information improves test reading accuracy [1].

Because there are no randomized trials assessing the effects of using imaging methods in women with gynecological problems, in this chapter I will focus on the reported sensitivity, specificity and likelihood ratios of imaging methods used in gynecology. Likelihood ratios indicate by how much a given test results will raise or lower the pretest probability of the target disorder. They reflect very well the clinical usefulness of a diagnostic test. Likelihood ratios $>10$ or $<0.1$ generate large and often conclusive changes from pre-test to post-test odds of the outcome, likelihood ratios of $5-10$ or $0.1-0.2$ generate moderate changes from pre-test to post-test odds, likelihood ratios of $2-5$ or $0.2-0.5$ generate only small changes from pre-test to post-test odds, and likelihood ratios of $1-2$ or $0.5-1$ do not change probabilities to any important degree [2]. I will add comments on the likely effect (not proven in randomized trials) of using imaging 
methods in clinical practice. I will not deal with imaging in gynecological oncology (staging of gynecological cancers, diagnosis of recurrence of gynecological cancer, diagnosis of trophoblastic tumors), imaging in infertility or in the diagnosis of Mullerian duct anomalies.

It is important to bear in mind that when it comes to diagnostic imaging methods it is not only the definition of an abnormal imaging result, the skill of the examiner or reader, and the quality of the equipment used that will determine the performance of the method but also the population studied. For example, if a study population of adnexal masses contains only masses that are easy to classify with an imaging method, sensitivity and specificity will be high, whereas if the study population contains only masses that are difficult to classify, sensitivity and specificity will be low; and in a study population comprising only of cases with advanced disease, the imaging method is likely to perform better than in a population comprising only of cases with mild disease.

Questions to be answered and literature sources are shown in Box 1.

Box 1

Questions and literature sources for imaging methods in gynecology

Question components

Population: women with gynecological problems

Interventions: imaging methods used to facilitate correct diagnosis (ultrasound, computer tomography, magnetic resonance imaging)

Outcomes: comparison with gold standard where available (sensitivity, specificity, likelihood ratios) 
Comments: possible effects on rate of correct diagnosis, time to correct diagnosis, and patient health in a short and long term perspective

Study designs: primary studies, systematic reviews, meta-analyses

Literature sources

Electronic databases: MEDLINE

Manual search: reference lists of original articles and review articles

\section{Bleeding and/or pain in early pregnancy}

A woman who presents with bleeding and/or pain in the first trimester may have one of the following four diagnoses: normal intrauterine pregnancy, failed intrauterine pregnancy, ectopic pregnancy, or trophoblastic disease. In most cases, anamnesis and clinical examination will not immediately yield a correct diagnosis. In a series of 772 consecutive women presenting with threatened abortion $<28$ gestational weeks the diagnosis suggested by the clinician on the basis of anamnesis and clinical examination agreed with the true diagnosis in only $75 \%$ of cases (576 of 772 cases, Kappa 0.57), whereas the diagnosis suggested after the clinician had added a transvaginal ultrasound examination agreed with the true diagnosis in $98 \%$ of cases $(757$ of 772 cases, Kappa 0.96) [3]. Ultrasound has become a very valuable - not to say indispensable diagnostic tool in the management of women with early pregnancy complications. That, in skilled hands, ultrasound diagnosis is quicker and more accurate than diagnosis without ultrasound is so obvious, that it requires no further confirmation in randomized trials.

The first question to be answered in a woman with bleeding and/or pain in early pregnancy is if the pregnancy is intrauterine or ectopic. In appropriately trained hands, a single transvaginal ultrasound examination can correctly confirm the presence of an intrauterine or ectopic 
pregnancy in $90 \%$ of cases $[4,5]$. In a prospective study of 6621 consecutive women with an early pregnancy, $85 \%$ of whom presented with pain and/or bleeding, tubal pregnancy was correctly diagnosed with transvaginal ultrasound with a sensitivity $91 \%$ and a specificity of $99.9 \%[5]$. The sensitivity and specificity of transvaginal ultrasound with regard to tubal pregnancy are shown in Table 1 [5-9]. The table shows that transvaginal ultrasound is an excellent method for confirming or excluding tubal pregnancy, but sensitivity and specificity are likely to depend highly on the skill of the examiner and on the quality of the ultrasound equipment used.

If an intrauterine gestational sac is found at transvaginal ultrasound examination in a woman with bleeding and/or pain in early pregnancy the following questions arise: Is there a living embryo/fetus? If there is a living embryo/fetus, how likely is it that the pregnancy will end in miscarriage? Some ultrasound findings have been suggested to exclude normal pregnancy: intrauterine gestational sac with a mean diameter of $\geq 8 \mathrm{~mm}$ but without a visible yolk sac [10], intrauterine gestational sac with a mean diameter of $\geq 16 \mathrm{~mm}$ but without a visible embryo with a heart beat [10], embryo with crown rump length of $\geq 4 \mathrm{~mm}$ but with no heart beat [11]. The sensitivity and specificity with regard to failed early pregnancy of various ultrasound findings that have been suggested to be diagnostic of non-viability are shown in Table 2 [10-15]. The sensitivity and specificity will depend on the skill of the ultrasound examiner, the quality of the ultrasound equipment and any presence of technical problems, e.g., large uterine fibromas obscuring the view of the uterine cavity. If there is the slightest uncertainty about the viability of the pregnancy, a diagnosis of pregnancy failure must not be made. Instead, the ultrasound examination should be repeated to assess the development of the pregnancy. Indeed, pregnancies fulfilling the above criteria of non-viability have resulted in live births [16]. Logistic regression 
models have been constructed to predict pregnancy outcome in intrauterine pregnancies with gestational sacs $<16 \mathrm{~mm}$ or $<20 \mathrm{~mm}$ without a visible embryo [17, 18], but these risk calculation models have not been tested prospectively.

Ultrasound examination can also be used to estimate the risk of miscarriage in pregnant women with bleeding but where the embryo/fetus has a beating heart at ultrasound examination. Falco et al [19] constructed a logistic regression model containing information on gestational sac diameter, crown-rump length and embryonic/fetal heart rate. The model had an area under the receiver operating characteristic (ROC) curve of 0.79 . Using a risk cut-off of $6 \%$ it predicted miscarriage with a sensitivity of $83 \%$ and a specificity of $71 \%$, corresponding to a positive likelihood ratio of 2.9 and a negative likelihood ratio of 0.2 . This shows that the model was not a very good diagnostic test. It has not been tested prospectively. A logistic regression model including ultrasound variables to predict the risk of demise of living embryos/fetuses has also been constructed for asymptomatic pregnant women who conceived in an assisted reproduction technology program. Using that model it seemed to be possible to predict miscarriage with a sensitivity of approximately $75 \%$ and a specificity of approximately $95 \%$, corresponding to a positive likelihood ratio of approximately 15 and a negative likelihood ratio of approximately 0.3 . This model, too, has not been prospectively cross-validated [20].

There are several reviews reporting on the accuracy of ultrasound examination in the diagnosis of early pregnancy failure [21-23].

Ultrasound diagnosis provides a basis for individually tailored treatment of women with spontaneous abortion or ectopic pregnancy, i.e., expectant management, medical treatment, or 
surgery [24-32]. Protocols for managing women with pregnancies with unknown location at ultrasound examination have also been developed [33-35].

Computer tomography (CT) is contraindicated in early pregnancy. Magnetic resonance imaging (MRI) can be used, but it plays no important role in the management of women with bleeding and pain in early pregnancy, because most diagnostic problems can be solved using ultrasound. MRI may contribute to the diagnosis of extremely rare pregnancy complications, e.g., ectopic pregnancy in spleen [36], liver [37], or retroperitoneum [38]. I have seen no reports on the sensitivity and specificity of MRI in the diagnosis of miscarriage or ectopic pregnancy.

\section{Postmenopausal bleeding}

Approximately $10 \%$ of women with postmenopausal bleeding have endometrial cancer [39]. Before the introduction of ultrasound examination virtually all women with postmenopausal bleeding underwent dilatation and curettage $(\mathrm{D} \& \mathrm{C})$ to confirm or exclude the diagnosis of endometrial cancer. However, there is strong scientific evidence that a transvaginal ultrasound examination with measurement of endometrial thickness can reliably discriminate between women with high and low risk of endometrial cancer. According to a meta-analysis [39], 96\% of women with endometrial cancer have endometrial thickness $\geq 5 \mathrm{~mm}$ (sensitivity $96 \%$ ) vs. $8 \%$ of those without cancer and not on hormone replacement therapy (specificity $92 \%$ ) and vs. $23 \%$ of those without cancer and on hormone replacement therapy (specificity 77\%). This means that a postmenopausal woman with vaginal bleeding not on hormone replacement therapy and a $10 \%$ pretest probability of endometrial cancer has a probability of cancer of $1 \%$ if her endometrium measures $\leq 4 \mathrm{~mm}$ at a transvaginal ultrasound examination. Management protocols have been developed where women with postmenopausal bleeding are primarily examined with transvaginal 
ultrasound and where only those with endometrium $\geq 5 \mathrm{~mm}$ undergo further investigations including saline infusion sonography (see below) or diagnostic hysteroscopy and endometrial sampling by one or the other method [40]. Such an approach does seem to be both safe [41] and cost-effective [42].

A different approach to using a simple endometrial thickness cutoff to classify a woman as being at high or low risk of endometrial cancer would be to use multiple logistic regression models including both clinical variables (e.g., age, use of hormone replacement therapy, parity, body mass index) and ultrasound variables (e.g., endometrial thickness, endometrial internal echogenicity, regularity of the endometrial-myometrial border, and possibly Doppler findings, see below) to calculate the individual risk of malignancy for each woman. Such models have been developed $[43,44][45,46]$, but none of these models has been validated prospectively in populations other than those where the models were created.

According to a meta-analysis of 24 studies, where all but two studies comprised both pre-and postmenopausal women, saline infusion sonography (infusion of sterile saline into the uterine cavity during scanning) makes it possible to detect focally growing lesions in the uterine cavity with a sensitivity of $95 \%$ and a specificity of $88 \%$ (positive and negative likelihood ratios 8 and 0.06) [47]. Agreement between office saline infusion sonography and hysteroscopy in general anesthesia with regard to detecting focal lesions in the uterine cavity is excellent in women with postmenopausal bleeding, disagreement between the two methods occurring in only three of 75 women in one study [48]. Most endometrial pathology in women with postmenopausal bleeding manifests a focal growth pattern at hysteroscopy, the likelihood of endometrial pathology increasing if focal lesions are seen in the cavity and decreasing if none are seen [49]. Many focal 
lesions will not be removed or only partially removed at a blind D\&C or endometrial biopsy [4952].Therefore, it has been suggested that women with postmenopausal bleeding and an endometrium measuring $\geq 5 \mathrm{~mm}$ at transvaginal ultrasound examination should undergo saline infusion sonography (as an alternative to diagnostic hysteroscopy), and that women with focal lesions at saline infusion sonography should undergo hysteroscopic resection of the focal lesions (not only blind endometrial sampling by D\&C or a simple outpatient sampling device), whereas it would suffice to submit women with no focal lesions in the uterine cavity to blind endometrial sampling . In a randomized crossover study comprising consecutive asymptomatic postmenopausal women, most women preferred saline infusion sonography to office hysteroscopy [53].

Various research teams have tried to refine the diagnosis of endometrial pathology by assessing the ultrasound morphology of the endometrium (e.g., regular or irregular endometrial-myometrial border, homogenous or inhomogenous internal endometrial echogenicity, hyperechoic lines surrounding the endometrial complex, echogenicity similar to that of myometrium) [54-61]. When sonomorphological criteria similar to those suggested in references $54-60$ were applied prospectively to 105 consecutive women with postmenopausal bleeding and endometrial thickness $\geq 5 \mathrm{~mm}$, the sensitivity and specificity with regard to endometrial polyp were $49 \%$ and $81 \%$ (positive and negative likelihood ratio 3 and 0.6 ), with regard to malignancy $60 \%$ and $90 \%$ (positive and negative likelihood ratio 6 and 0.4 ), and with regard to submucuous myoma 30\% and $97 \%$ (positive and negative likelihood ratio 10 and 0.7 ). The sensitivity and specificity of hysteroscopy in general anesthesia in the same cohort of women were $81 \%$ and $94 \%$ for endometrial polyp (positive and negative likelihood ratio 14 and 0.2 ), $84 \%$ and $85 \%$ for endometrial cancer (positive and negative likelihood ratio 6 and 0.2 ) and $67 \%$ and $97 \%$ for 
submucuous myoma (positive and negative likelihood ratio 22 and 0.3 ). This shows that in this particular cohort of women with postmenopausal bleeding, hysteroscopy was superior to transvaginal ultrasound examination with regard to the diagnosis of polyps and submucuous myomas, whereas the performance was similar with regard to endometrial cancer. Saline infusion sonography was successful in 78 of the 105 women. It had a sensitivity and specificity with regard to endometrial polyp of $79 \%$ and $76 \%$ (positive and negative likelihood ratio 2.3 and 0.3 ), with regard to endometrial cancer $44 \%$ and $94 \%$ (positive and negative likelihood ratio 7 and 0.6), and with regard to submucuous myoma of $80 \%$ and $99 \%$ (positive and negative likelihood ratio 80 and 0.2 .). Both at saline infusion sonography and at hysteroscopy benign polyps were confused with endometrial cancer and vice versa [48].This shows that neither saline infusion sonography nor hysteroscopy can reliably discriminate between benign and malignant focal lesions in the uterine cavity in women with postmenopausal bleeding.

Concerns have been raised that saline infusion sonography and hysteroscopy might lead to intraperitoneal dissemination of malignant cells in women with endometrial cancer. It seems that a small risk of malignant cell dissemination exists in patients with endometrial carcinoma who undergo saline infusion sonography [62]. On the other hand, 5-year survival has been reported to be the same in women with early endometrial cancer who have undergone hystesteroscopy before laparotomy as in those who have not undergone preoperative hysteroscopy [63].

Attempts have been made to discriminate between various types of endometrial pathology by studying the vascularity of the uterus or endometrium using color- power- or spectral Doppler ultrasound [46, 64-68]. In one study, analysis of the color content of the endometrial scan contributed to the diagnosis of endometrial cancer in women with postmenopausal bleeding [46], 
but the role of Doppler ultrasound examination in the diagnosis of endometrial pathology in women with postmenopausal bleeding is not yet clear.

There are no publications on the use of ultrasound contrast as a diagnostic tool in women with postmenopausal bleeding. MRI and CT have no role in the primary investigation of women with postmenopausal bleeding, even though both methods can been used for staging of endometrial cancer [69] and for diagnosis of recurrence of endometrial cancer.

Transvaginal ultrasound examination enables reliable discrimination between women with postmenopausal bleeding at high and low risk of endometrial cancer. This makes it possible to tailor management to each individual woman.

\section{Bleeding disturbances before the menopause}

Common causes of bleeding disturbances in non-pregnant women before the menopause are hormonal dysfunction (e.g., anovulatory bleeding), hormonal treatment (e.g., contraceptive pills), intrauterine contraceptive devices, and infections. None of these causes can be definitely established by using an imaging method. Imaging methods can only be used to confirm or refute an anatomical abnormality, e.g., a submucuous myoma, an endometrial polyp, or adenomyosis. These may or may not be the cause of the bleeding problem. Endometrial cancer is an uncommon cause of bleeding disturbance in women before the menopause. A review of the diagnostic accuracy of transvaginal ultrasound, saline infusion sonography, hysteroscopy and MRI with regard to abnormalities in the uterine cavity in premenopausal women has been published by Dueholm et al [70]. 
Two appropriately designed studies (hysterectomy as gold standard, blinded examiners) compared the diagnostic accuracy with regard to uterine cavity abnormalities of various imaging methods in premenopausal women $[71,72]$. In one of the studies, MRI was found to be superior to transvaginal sonography, saline infusion sonography and hysteroscopy for correct determination of the exact ingrowth of submucuous myomas into the uterine cavity [71]. Other results of the two studies are summarized in Table 3. They show that saline infusion sonography is a good method for showing/excluding pathology in the uterine cavity in premenopausal women.

The problem is, that even if one finds a submucuous myomas or an endometrial polyp in the uterine cavity of a premenopausal woman with bleeding problems, one cannot be sure that these are the cause of the abnormal bleeding. Endometrial polyps are common $(10 \%)$ in asymptomatic women, and submucuous myomas are also not uncommon (3\%) (data from a population study presented at the World Congress of the International Society of Ultrasound in Obstetrics and Gynecology in 2003 by Dr E Dreisler, Denmark). One randomized controlled trial compared various methods of assessing the endometrium with regard to performance, patient acceptability, and cost-effectiveness, the assssment being done in three groups of women, i.e., women with postmenopausal bleeding, women $\geq 40$ years old with abnormal bleeding, and women $<40$ years old with abnormal bleeding [73]. There is no unequivocal evidence whether the most efficient way of managing women with abnormal bleeding before the menopause would be to use an imaging method as a first line investigation or if it would be to use an imaging methods only when there is a strong clinical suspicion of an anatomical abnormality causing the bleeding.

\section{Imaging methods used to diagnose uterine myoma, adenomyoma, and leiomyosarcoma}


Ultrasound and MRI can be used to diagnose uterine myomas. Differential diagnoses are adenomyoma, benign solid ovarian tumors, e.g. ovarian fibroma / fibrothecoma (in case of myoma on a stalk) and leiomyosarcoma [74]. Most myomas have a very typical appearance at ultrasound examination $[74,75]$. Using the 'refractory shadowing pattern' in 222 pelvic masses, myomas were diagnosed using transvaginal ultrasound with a sensitivity of $87 \%$ and a specificity of $89 \%$. This corresponds to a positive likelihood ratio of 8 and a negative likelihood ratio of 0.15. In a study comparing ultrasound with MRI, transvaginal ultrasound and MRI had similar ability to diagnose uterine myomas, the sensitivity, specificity, positive and negative likelihood ratio for ultrasound being $99 \%, 91 \%, 11$ and 0.01 vs. $99 \%, 86 \%, 7$ and 0.13 for MRI [76]. MRI was superior to ultrasound for determining the exact location of myomas, particularly in large uteri with more than four myomas [76]. Neither ultrasound nor MRI seems to be able to reliably discriminate between uterine leiomyoma and leiomyosarcoma [77-79]. Transvaginal ultrasound can distinguish myomas from adenomyomas (Table 4)[80-82], but I have found no publication describing the sensitivity and specificity of MRI with regard to adenomyoma.

Adenomyosis can be fairly confidently diagnosed using transvaginal ultrasound or MRI (Table 5)[83-91]. For both methods the diagnostic performance varies enormously between studies. I have seen no publications on the diagnostic performance of CT with regard to adenomyosis.

\section{Palpable pelvic mass}

A pelvic mass may be found in a woman presenting with gynecological complaints, in which case it may or may not be related to her symptoms. It may also be an incidental finding in a woman with no gynecological problems. Whatever the case, a pelvic mass usually raises anxiety, 
because it may be a malignancy. Therefore, imaging methods - particularly ultrasound - are often used to help make a correct diagnosis, so that appropriate treatment can be chosen.

Ultrasound examination in skilled hands is an excellent tool for distinguishing benign from malignant adnexal masses [92, 93]. It may also be used to make a specific diagnosis, e.g., dermoid cyst, endometrioma, hydrosalpinx, etcetera [94]. Experienced ultrasound examiners usually use "pattern recognition", i.e., subjective evaluation of the gray scale ultrasound image (sometimes supplemented by color- power- or spectral Doppler ultrasound) to make a diagnosis of an adnexal mass [94]. Ultrasound morphology of various types of adnexal pathology is described in reference [74] and the diagnostic value of adding Doppler ultrasound to gray scale imaging is thoroughly discussed in reference [95]. The sensitivity and specificity of pattern recognition both with regard to malignancy and specific diagnoses are shown in Table $6[94,96-$ 109]. A meta-analysis describing the diagnostic accuracy of transvaginal ultrasound specifically for the diagnosis of endometriomas has been published [110].

In studies where pattern recognition was compared to other ultrasound methods (Lerner score [111], risk of malignancy index [112], the Tailor risk calculation model [113], the Timmerman risk calculation model [114] and the mathematical risk calculation models designed in the International Ovarian Tumor Analysis (IOTA) study [115]), pattern recognition was superior to the other methods for distinguishing benign from malignant adnexal masses (Table 7)[115-117]. Because the diagnostic performance of pattern recognition improves with experience[93], scoring systems or logistic regression models to calculate an individual risk of malignancy might work better for less experienced ultrasound examiners. However, whether this is indeed the case has not been studied. Some of the risk calculation models (the Timmerman model [114], the Tailor 
model[113]) and scoring systems (the Sassone score [118], the Lerner score [111], the De Priest score [119]) did not perform very well when they were tested prospectively $[116,117,120,121]$. The IOTA models [115] and the Ferrazzi score[120] have not yet been prospectively crossvalidated.

Two studies have examined the contribution of three dimensional (3D) power Doppler ultrasound examination to a correct diagnosis of an adnexal mass. One of them found 3D power Doppler to improve sensitivity and specificity with regard to malignancy [122], the other did not [123]. The possibility to use ultrasound contrast for evaluating adnexal masses has been discussed in two publications $[124,125]$, but there are not yet any published studies describing the clinical usefulness of using ultrasound contrast.

Not all adnexal masses are easily classified as benign or malignant using pattern recognition. Borderline tumors, papillary cystadeno(fibro)mas and struma ovarii are particularly difficult to classify [126]. For these 'difficult tumors' another diagnostic method would be needed, but currently a method capable of distinguishing benign from malignant 'difficult masses' is lacking. Another diagnostic problem is to distinguish borderline epithelial ovarian malignancies from stage I epithelial ovarian cancers. It does not seem to be possible to distinguish these two entities using either ultrasound, CT or MRI [127, 128].

Ultrasound has been found to be as good as or superior to CT for discrimination between different types of pelvic tumor $[109,129]$. MRI has also been used to characterize different types of adnexal tumor in the female pelvis [130-136]. MRI can recognize specific types of tissue, e.g., blood (endometriomas, haemorrhagic cysts), fat (dermoid cysts), and fibrous tissue (fibromas) 
[136]. The value of adding CT or MRI to ultrasound imaging in 'indeterminate ovarian masses was studied in a meta-analysis. The results showed that MRI was superior to CT [137]. In another study, MRI was found to be superior to ultrasound for discriminating between benign and malignant adnexal masses, because it was associated with fewer false positive results [138]. However, in that study it was mainly haemorrhagic cysts, endometriomas and dermoid cysts that comprised the false positive ultrasound results. Therefore, the skill of the ultrasound examiner must be questioned, because in the hands of a skilled ultrasound examiner hemorrhagic cysts, endometriomas and dermoid cysts very rarely cause diagnostic problems, see Table 6.

High quality ultrasound is the imaging method of choice in the differential diagnosis of adnexal masses in most cases. It is simpler, cheaper, and quicker than both CT and MRI, it is readily available and safe, and in skilled hands it will yield a correct diagnosis in most cases (Table 6). A reliable diagnosis makes it possible to choose optimal treatment.

\section{Pelvic pain}

\section{Acute pelvic pain}

There are a number of acutely painful conditions where an ultrasound examination, particularly a transvaginal ultrasound examination, can contribute to a correct diagnosis: ovarian cysts and tumors (although they do not always cause pain), torsion of the adnexa, and pelvic inflammatory disease, PID, (pyosalpinx, tubo-ovarian abscess, early salpingitis).

The sensitivity and specificity of ultrasound with regard to different types of adnexal masses are presented in Table 6. 
Ultrasound findings typical of pelvic inflammatory disease have been described by Timor-Tritsch et al [139] and by Molander et al [140]. The sensitivity and specificity of ultrasound with regard to PID are shown in Table 8 [141-144]. The variable results may be explained by differences in stage of inflammation, ultrasound criteria of PID, skill of the examiner, and quality of the ultrasound systems used.

Even though there are many studies describing features typical of adnexal torsion at ultrasound examination [145-150], CT and MRI $[151,152]$, there is only one study reporting data that enables calculation of sensitivity and specificity with regard to adnexal torsion: in a study of 65 women with clinical suspicion of adnexal torsion, abnormal color Doppler findings in an adnexal mass predicted torsion $(n=15)$ with a sensitivity of $100 \%$ and a specificity of $98 \%$ [153].

\section{Chronic pelvic pain}

There is no agreed definition of chronic pelvic pain and there is much controversy about what may cause it [154]. Some believe that peritoneal endometriosis and pelvic adhesions cause chronic pelvic pain [155]. Adenomyosis may also be associated with pelvic pain. Imaging methods to diagnose adenomyosis have been described above (Table 5). Okaro et al [156] invented the ultrasound term 'soft marker' to indicate pelvic pathology in women with chronic pelvic pain, the 'soft markers' being presence of immobile ovaries and/or site specific tenderness and/or loculated pelvic fluid at transvaginal ultrasound examination. They found these soft markers to indicate significant pelvic pathology with a positive likelihood ratio of 1.9 and a negative likelihood ratio of 0.2 . i.e., the absence of soft markers substantially decreased the likelihood of finding pelvic pathology at laparoscopy. Possibly, the use of soft markers could reduce the number of unnecessary laparoscopies performed in women with chronic pelvic pain, 
but the results of Okaro et al would nee to be reproduced by others before being universally adopted.

\section{Endometriosis}

I know of no study that has compared clinical examination to imaging methods with regard to diagnosing peritoneal endometriosis. Clinical examination alone does not seem to be a good method for detecting peritoneal endometriosis [157]. The sensitivity and specificity of ultrasound and MRI with regard to various forms of peritoneal endometriosis are shown in Table 9 [158167]. Results are extremely variable. One study found ultrasound staging of pelvic endometriosis to agree with laparoscopic staging in $82 \%$ of cases [168]. I have found no studies reporting the diagnostic performance of CT for the diagnosis of peritoneal endometriosis.

\section{Pelvic adhesions}

There are few publications describing the diagnostic accuracy of various imaging methods in the diagnosis of pelvic adhesions. Guerriero and colleagues determined the sensitivity and specificity of various ultrasound findings (blurred margins of the ovary, fixed ovary, distance between ultrasound probe and ovary) and various combinations of ultrasound findings and clinical findings with regard to laparoscopically diagnosed pelvic adhesions in women with risk factors for pelvic adhesions [169]. They also constructed a logistic regression model to calculate the likelihood of pelvic adhesions, but they did not report the sensitivity and specificity of the model, and to the best of my knowledge it has not been tested prospectively. Most ultrasound findings and their combinations changed the odds of pelvic adhesions only little (positive likelihood ratios ranging from 2.6to 6.1, and negative likelihood ratios ranging from 0.4 to 0.7 ). Ubaldi and coworkers found poor definition of pelvic structures at transvaginal ultrasound examination to 
predict pelvic adhesions at laparoscopy with a sensitivity of $61 \%$ and a specificity of $98 \%$ (positive likelihood ratio 30.5, negative likelihood ratio of 0.6) [170]. The results of Guerriero et al and Ubaldi et al point in the same direction: ultrasound findings suggestive of pelvic adhesions substantially increase the risk of adhesions, but absence of suspicious ultrasound findings does not decrease the risk very much. Three-dimensional ultrasound combined with analysis of serum Ca 125 has been reported to have a sensitivity of $90 \%$ and a specificity of $100 \%$ for the diagnosis of pelvic adhesions (negative likelihood ratio of 0.1) [171], whereas MRI has been reported to have a sensitivity of $73 \%$ and a specificity of $87 \%$ (positive likelihood ratio 6 , negative likelihood ratio of 0.3) [172]. I have found no reports on the diagnostic performance of CT for the diagnosis of pelvic adhesions.

\section{Summary}

Ultrasound is the first line imaging method in the differential diagnosis of most gynecological diseases and tumors. It can diagnose tubal pregnancy with a sensitivity of $91 \%$ and a specificity of $99.9 \%$, it can diagnose malignancy in an adnexal mass with a sensitivity of $88 \%$ and a specificity of $96 \%$, it can discriminate between benign and malignant endometrium in women with postmenopausal bleeding not on hormone replacement therapy of with a sensitivity of $96 \%$ and a specificity of $92 \%$, it can diagnose adenomyosis with a sensitivity of $87 \%$ and a specificity of $96 \%$, which is similar to the sensitivity and specificity reported for MRI. Ultrasound may also be used in the diagnosis of pelvic inflammatory disease, the finding of a thick walled fluid filled tube at ultrasound examination having been found to have a sensitivity of $85 \%$ and a specificity of $100 \%$. Transvaginal or transrectal ultrasound can be used to diagnose endometriosis in the recto-vaginal septum and utero-sacral ligaments, but MRI may be an as good or even better 
imaging method for these entities. The role of 3D ultrasound and ultrasound contrast is not yet clear.

\section{Practice points}

\section{Bleeding and pain in early pregnancy}

- Ultrasound signs of early pregnancy failure have been described (mean gestational sac diameter $\geq 8 \mathrm{~mm}$ but no visible yolk sac, mean gestational sac diameter $\geq 16 \mathrm{~mm}$ but no visible embryo with heart beat, embryo $\geq 5 \mathrm{~mm}$ without heart beat), but none of these signs completely exclude a viable pregnancy

- If there is the slightest uncertainty about the viability of an early pregnancy (for example because of a technically difficult examination), a diagnosis of pregnancy failure must not be made. Instead, the ultrasound examination should be repeated to assess the development of the pregnancy.

\section{Postmenopausal bleeding}

- Measurement of endometrial thickness is a simple and accurate method for estimating the risk of endometrial malignancy, endometrial thickness $\leq 4 \mathrm{~mm}$ indicating low risk and endometrial thickness $\geq 5 \mathrm{~mm}$ indicating high risk

- Endometrial morphology at grey scale ultrasound examination with or without saline infusion cannot reliably discriminate between benign and malignant endometrial lesions

- The role of 3D ultrasound, color- power- or spectral-Doppler ultrasound with regard to predicting endometrial malignancy is uncertain 
Pelvic masses

- The 'refractory shadowing pattern' ('stripes') is typical of uterine leiomyomas at ultrasound examination

- The presence of both solid components and irregularity in an adnexal mass at ultrasound examination makes malignancy likely

- Neither ultrasound nor CT nor MRI can reliably discriminate between an epithelial borderline ovarian tumor and a stage I epithelial ovarian cancer

- The role of 3D ultrasound and ultrasound contrast in the differential diagnosis of adnexal masses is uncertain

Pelvic pain

- Neither ultrasound (not even Doppler ultrasound) nor CT nor MRI can reliably exclude adnexal torsion in a woman with acute pelvic pain

- Neither ultrasound nor CT nor MRI can reliably exclude pelvic adhesions

- The reported diagnostic performance of ultrasound and MRI for the diagnosis of 'deep endometriosis' varies considerably between studies, and it is not possible to recommend one method over the other

- The diagnostic performance of ultrasound and MRI with regard to adenomyosis is probably similar

\section{Research agenda}

- The clinical value of 3D ultrasound examination (including 3D hydrosonography and 3D power Doppler) in gynecology needs to be determined

- The role of ultrasound contrast in gynecology needs to be determined 
- Better multiple logistic regression models to estimate the risk of endometrial malignancy in women with postmenopausal bleeding need to be developed and tested prospectively

- Grey scale and Doppler ultrasound characteristics of various types of endometrial pathology need to be defined

- The clinical significance of the presence of focal lesions in the uterine cavity at ultrasound examination in asymptomatic women of fertile age needs to be determined

- Imaging features (or other diagnostic methods) that can confidently discriminate between borderline ovarian tumors and stage I invasive ovarian tumors need to be defined

- Ultrasound features that can confidently discriminate between benign, borderline, and invasive ovarian tumors with papillary projections need to be defined 


\section{References}

1. Loy CT, Irwig L. Accuracy of diagnostic tests read with and without clinical information: a systematic review. Jama. 2004 Oct 6;292(13):1602-9.

2. Jaeschke R, Guyatt GH, Sackett DL. Users' guides to the medical literature. III. How to use an article about a diagnostic test. B. What are the results and will they help me in caring for my patients? The Evidence-Based Medicine Working Group. Jama. 1994 Mar 2;271(9):703-7.

3. Yip SK, Sahota D, Cheung LP, Lam P, Haines CJ, Chung TK. Accuracy of clinical diagnostic methods of threatened abortion. Gynecol Obstet Invest. 2003;56(1):38-42.

4. Cacciatore B, Stenman UH, Ylostalo P. Comparison of abdominal and vaginal sonography in suspected ectopic pregnancy. Obstet Gynecol. 1989 May;73(5 Pt 1):770-4.

5. Condous G, Okaro E, Khalid A, Lu C, Van Huffel S, Timmerman D, et al. The accuracy of transvaginal ultrasonography for the diagnosis of ectopic pregnancy prior to surgery. Hum Reprod. 2005 May;20(5):1404-9.

6. Brown DL, Doubilet PM. Transvaginal sonography for diagnosing ectopic pregnancy: positivity criteria and performance characteristics. J Ultrasound Med. 1994 Apr;13(4):259-66.

$7 . \quad H o p p$ H, Schaar P, Entezami M, Ebert A, Hundertmark S, Vollert W, et al. [Diagnostic reliability of vaginal ultrasound in ectopic pregnancy]. Geburtshilfe Frauenheilkd. 1995 Dec;55(12):666-70.

8. Kaplan BC, Dart RG, Moskos M, Kuligowska E, Chun B, Adel Hamid M, et al. Ectopic pregnancy: prospective study with improved diagnostic accuracy. Ann Emerg Med. 1996 Jul;28(1):10-7.

9. Shalev E, Yarom I, Bustan M, Weiner E, Ben-Shlomo I. Transvaginal sonography as the ultimate diagnostic tool for the management of ectopic pregnancy: experience with 840 cases. Fertil Steril. 1998 Jan;69(1):62-5.

10. Levi CS, Lyons EA, Lindsay DJ. Early diagnosis of nonviable pregnancy with endovaginal US. Radiology. 1988 May;167(2):383-5.

11. Goldstein SR. Significance of cardiac activity on endovaginal ultrasound in very early embryos. Obstet Gynecol. 1992 Oct;80(4):670-2.

12. Brown DL, Emerson DS, Felker RE, Cartier MS, Smith WC. Diagnosis of early embryonic demise by endovaginal sonography. J Ultrasound Med. 1990 Nov;9(11):631-6.

13. Levi CS, Lyons EA, Zheng XH, Lindsay DJ, Holt SC. Endovaginal US: demonstration of cardiac activity in embryos of less than $5.0 \mathrm{~mm}$ in crown-rump length. Radiology. $1990 \mathrm{Jul} ; 176(1): 71-4$.

14. Schouwink MH, Fong BF, Mol BW, van der Veen F. Ultrasonographic criteria for non-viability of first trimester intra-uterine pregnancy. Early Pregnancy. 2000 Jul;4(3):203-13.

15. Tongsong T, Wanapirak C, Srisomboon J, Sirichotiyakul S, Polsrisuthikul T, Pongsatha S. Transvaginal ultrasound in threatened abortions with empty gestational sacs. Int J Gynaecol Obstet. 1994 Sep;46(3):297-301.

16. Rowling SE, Coleman BG, Langer JE, Arger PH, Nisenbaum HL, Horii SC. Firsttrimester US parameters of failed pregnancy. Radiology. 1997 Apr;203(1):211-7.

17. Elson J, Salim R, Tailor A, Banerjee S, Zosmer N, Jurkovic D. Prediction of early pregnancy viability in the absence of an ultrasonically detectable embryo. Ultrasound Obstet Gynecol. 2003 Jan;21(1):57-61. 
18. Falco P, Zagonari S, Gabrielli S, Bevini M, Pilu G, Bovicelli L. Sonography of pregnancies with first-trimester bleeding and a small intrauterine gestational sac without a demonstrable embryo. Ultrasound Obstet Gynecol. 2003 Jan;21(1):62-5.

19. Falco P, Milano V, Pilu G, David C, Grisolia G, Rizzo N, et al. Sonography of pregnancies with first-trimester bleeding and a viable embryo: a study of prognostic indicators by logistic regression analysis. Ultrasound Obstet Gynecol. 1996 Mar;7(3):165-9.

20. Choong S, Rombauts L, Ugoni A, Meagher S. Ultrasound prediction of risk of spontaneous miscarriage in live embryos from assisted conceptions. Ultrasound Obstet Gynecol. 2003 Dec;22(6):571-7.

21. Nyberg DA, Filly RA. Predicting pregnancy failure in 'empty' gestational sacs. Ultrasound Obstet Gynecol. 2003 Jan;21(1):9-12.

22. Sotiriadis A, Papatheodorou S, Makrydimas G. Threatened miscarriage: evaluation and management. Bmj. 2004 Jul 17;329(7458):152-5.

23. Jauniaux E, Johns J, Burton GJ. The role of ultrasound imaging in diagnosing and investigating early pregnancy failure. Ultrasound Obstet Gynecol. 2005 Jun;25(6):613-24.

24. Nielsen S, Hahlin M. Expectant management of first-trimester spontaneous abortion. Lancet. 1995 Jan 14;345(8942):84-6.

25. Hajenius PJ, Engelsbel S, Mol BW, Van der Veen F, Ankum WM, Bossuyt PM, et al. Randomised trial of systemic methotrexate versus laparoscopic salpingostomy in tubal pregnancy. Lancet. 1997 Sep 13;350(9080):774-9.

26. Gjelland K, Hordnes K, Tjugum J, Augensen K, Bergsjo P. Treatment of ectopic pregnancy by local injection of hypertonic glucose: a randomized trial comparing administration guided by transvaginal ultrasound or laparoscopy. Acta Obstet Gynecol Scand. 1995 Sep;74(8):629-34.

27. Korhonen J, Stenman UH, Ylostalo P. Low-dose oral methotrexate with expectant management of ectopic pregnancy. Obstet Gynecol. 1996 Nov;88(5):775-8.

28. Graziosi GC, Mol BW, Ankum WM, Bruinse HW. Management of early pregnancy loss. Int J Gynaecol Obstet. 2004 Sep;86(3):337-46.

29. Condous G, Okaro E, Bourne T. The conservative management of early pregnancy complications: a review of the literature. Ultrasound Obstet Gynecol. 2003 Oct;22(4):420-30.

30. Kirk E, Condous G, Bourne T. The non-surgical management of ectopic pregnancy. Ultrasound Obstet Gynecol. 2006 Jan;27(1):91-100.

31. Elson J, Tailor A, Banerjee S, Salim R, Hillaby K, Jurkovic D. Expectant management of tubal ectopic pregnancy: prediction of successful outcome using decision tree analysis. Ultrasound Obstet Gynecol. 2004 Jun;23(6):552-6.

32. Elson J, Tailor A, Salim R, Hillaby K, Dew T, Jurkovic D. Expectant management of miscarriage--prediction of outcome using ultrasound and novel biochemical markers. Hum Reprod. 2005 Aug;20(8):2330-3.

33. Banerjee S, Aslam N, Woelfer B, Lawrence A, Elson J, Jurkovic D. Expectant management of early pregnancies of unknown location: a prospective evaluation of methods to predict spontaneous resolution of pregnancy. Bjog. 2001 Feb;108(2):158-63.

34. Kirk E, Condous G, Haider Z, Lu C, Van Huffel S, Timmerman D, et al. The practical application of a mathematical model to predict the outcome of pregnancies of unknown location. Ultrasound Obstet Gynecol. 2006 Feb 2;27(3):311-5.

35. Condous G, Okaro E, Khalid A, Timmerman D, Lu C, Zhou Y, et al. The use of a new logistic regression model for predicting the outcome of pregnancies of unknown location. Hum Reprod. 2004 Aug;19(8):1900-10. 
36. Kitade M, Takeuchi H, Kikuchi I, Shimanuki H, Kumakiri J, Kinoshita K. A case of simultaneous tubal-splenic pregnancy after assisted reproductive technology. Fertil Steril. 2005 Apr;83(4):1042.

37. Harris GJ, Al-Jurf AS, Yuh WT, Abu-Yousef MM. Intrahepatic pregnancy. A unique opportunity for evaluation with sonography, computed tomography, and magnetic resonance imaging. Jama. 1989 Feb 10;261(6):902-4.

38. Terrier JP, Garcia S, Hardwigsen J, D'Ercole C, Andrac-Meyer L, Charpin C. [Retroperitoneal ectopic pregnancy: report of a case]. Ann Pathol. 1998 Jul;18(3):201-2.

39. Smith-Bindman R, Kerlikowske K, Feldstein VA, Subak L, Scheidler J, Segal M, et al. Endovaginal ultrasound to exclude endometrial cancer and other endometrial abnormalities. Jama. 1998 Nov 4;280(17):1510-7.

40. $\quad$ Epstein E, Valentin L. Managing women with post-menopausal bleeding. Best Pract Res Clin Obstet Gynaecol. 2004 Feb;18(1):125-43.

41. Gull B, Carlsson S, Karlsson B, Ylostalo P, Milsom I, Granberg S. Transvaginal ultrasonography of the endometrium in women with postmenopausal bleeding: is it always necessary to perform an endometrial biopsy? Am J Obstet Gynecol. 2000 Mar;182(3):509-15.

42. Dijkhuizen FP, Mol BW, Brolmann HA, Heintz AP. Cost-effectiveness of the use of transvaginal sonography in the evaluation of postmenopausal bleeding. Maturitas. 2003 Aug 20;45(4):275-82.

43. Bruchim I, Biron-Shental T, Altaras MM, Fishman A, Beyth Y, Tepper R, et al. Combination of endometrial thickness and time since menopause in predicting endometrial cancer in women with postmenopausal bleeding. J Clin Ultrasound. 2004 Jun;32(5):219-24. 44. Randelzhofer B, Prompeler HJ, Sauerbrei W, Madjar H, Emons G. Value of sonomorphological criteria of the endometrium in women with postmenopausal bleeding: a multivariate analysis. Ultrasound Obstet Gynecol. 2002 Jan;19(1):62-8.

45. Ferrazzi E, Torri V, Trio D, Zannoni E, Filiberto S, Dordoni D. Sonographic endometrial thickness: a useful test to predict atrophy in patients with postmenopausal bleeding. An Italian multicenter study. Ultrasound Obstet Gynecol. 1996 May;7(5):315-21.

46. Epstein E, Skoog L, Isberg PE, De Smet F, De Moor B, Olofsson PA, et al. An algorithm including results of gray-scale and power Doppler ultrasound examination to predict endometrial malignancy in women with postmenopausal bleeding. Ultrasound Obstet Gynecol. 2002 Oct;20(4):370-6.

47. de Kroon CD, de Bock GH, Dieben SW, Jansen FW. Saline contrast hysterosonography in abnormal uterine bleeding: a systematic review and meta-analysis. Bjog. 2003 Oct;110(10):938-47.

48. Epstein E, Ramirez A, Skoog L, Valentin L. Transvaginal sonography, saline contrast sonohysterography and hysteroscopy for the investigation of women with postmenopausal bleeding and endometrium $>5 \mathrm{~mm}$. Ultrasound Obstet Gynecol. 2001 Aug;18(2):157-62.

49. Epstein E, Ramirez A, Skoog L, Valentin L. Dilatation and curettage fails to detect most focal lesions in the uterine cavity in women with postmenopausal bleeding. Acta Obstet Gynecol Scand. 2001 Dec;80(12):1131-6.

50. Stovall TG, Solomon SK, Ling FW. Endometrial sampling prior to hysterectomy. Obstet Gynecol. 1989 Mar;73(3 Pt 1):405-9.

51. Valle RF. Hysteroscopic evaluation of patients with abnormal uterine bleeding. Surg Gynecol Obstet. 1981 Oct;153(4):521-6. 
52. Dubinsky TJ, Parvey HR, Gormaz G, Curtis M, Maklad N. Transvaginal hysterosonography: comparison with biopsy in the evaluation of postmenopausal bleeding. $\mathrm{J}$ Ultrasound Med. 1995 Dec;14(12):887-93.

53. Timmerman D, Deprest J, Bourne T, Van den Berghe I, Collins WP, Vergote I. A randomized trial on the use of ultrasonography or office hysteroscopy for endometrial assessment in postmenopausal patients with breast cancer who were treated with tamoxifen. Am J Obstet Gynecol. 1998 Jul;179(1):62-70.

54. Atri M, Nazarnia S, Aldis AE, Reinhold C, Bret PM, Kintzen G. Transvaginal US appearance of endometrial abnormalities. Radiographics. 1994 May;14(3):483-92.

55. Baldwin MT, Dudiak KM, Gorman B, Marks CA. Focal intracavitary masses recognized with the hyperechoic line sign at endovaginal US and characterized with hysterosonography. Radiographics. 1999 Jul-Aug;19(4):927-35.

56. Hulka CA, Hall DA, McCarthy K, Simeone JF. Endometrial polyps, hyperplasia, and carcinoma in postmenopausal women: differentiation with endovaginal sonography. Radiology. 1994 Jun;191(3):755-8.

57. Parsons AK, Lense JJ. Sonohysterography for endometrial abnormalities: preliminary results. J Clin Ultrasound. 1993 Feb;21(2):87-95.

58. Laifer-Narin SL, Ragavendra N, Lu DS, Sayre J, Perrella RR, Grant EG. Transvaginal saline hysterosonography: characteristics distinguishing malignant and various benign conditions. AJR Am J Roentgenol. 1999 Jun;172(6):1513-20.

59. Sheikh M, Sawhney S, Khurana A, Al-Yatama M. Alteration of sonographic texture of the endometrium in post-menopausal bleeding. A guide to further management. Acta Obstet Gynecol Scand. 2000 Nov;79(11):1006-10.

60. Caspi B, Appelman Z, Goldchmit R, Ashkenazi M, Haruvy Y, Hagay Z. The bright edge of the endometrial polyp. Ultrasound Obstet Gynecol. 2000 Apr;15(4):327-30.

61. Epstein E, Valentin L. Grey scale ultrasound morphology and endometrial vascularity as assessed by color Doppler ultrasound before and during saline infusion for discrimination between benign and malignant endometrium in women with postmenopausal bleeding Ultrasound Obstet Gynecol. 2006; In press.

62. Alcazar JL, Errasti T, Zornoza A. Saline infusion sonohysterography in endometrial cancer: assessment of malignant cells dissemination risk. Acta Obstet Gynecol Scand. 2000 Apr;79(4):321-2.

63. Obermair A, Geramou M, Gucer F, Denison U, Graf AH, Kapshammer E, et al. Impact of hysteroscopy on disease-free survival in clinically stage I endometrial cancer patients. Int J Gynecol Cancer. 2000 Jul;10(4):275-9.

64. Sladkevicius P, Valentin L, Marsal K. Endometrial thickness and Doppler velocimetry of the uterine arteries as discriminators of endometrial status in women with postmenopausal bleeding: a comparative study. Am J Obstet Gynecol. 1994 Sep;171(3):722-8. 65. Alcazar JL, Castillo G, Minguez JA, Galan MJ. Endometrial blood flow mapping using transvaginal power Doppler sonography in women with postmenopausal bleeding and thickened endometrium. Ultrasound Obstet Gynecol. 2003 Jun;21(6):583-8.

66. Fleischer AC, Shappell HW. Color Doppler sonohysterography of endometrial polyps and submucosal fibroids. J Ultrasound Med. 2003 Jun;22(6):601-4.

67. Amit A, Weiner Z, Ganem N, Kerner H, Edwards CL, Kaplan A, et al. The diagnostic value of power Doppler measurements in the endometrium of women with postmenopausal bleeding. Gynecol Oncol. 2000 May;77(2):243-7. 
68. Sheth S, Hamper UM, McCollum ME, Caskey CI, Rosenshein NB, Kurman RJ. Endometrial blood flow analysis in postmenopausal women: can it help differentiate benign from malignant causes of endometrial thickening? Radiology. 1995 Jun;195(3):661-5.

69. Kinkel K, Kaji Y, Yu KK, Segal MR, Lu Y, Powell CB, et al. Radiologic staging in patients with endometrial cancer: a meta-analysis. Radiology. 1999 Sep;212(3):711-8.

70. Dueholm M, Lundorf E, Olesen F. Imaging techniques for evaluation of the uterine cavity and endometrium in premenopausal patients before minimally invasive surgery. Obstet Gynecol Surv. 2002 Jun;57(6):388-403.

71. Dueholm M, Lundorf E, Hansen ES, Ledertoug S, Olesen F. Evaluation of the uterine cavity with magnetic resonance imaging, transvaginal sonography, hysterosonographic examination, and diagnostic hysteroscopy. Fertil Steril. 2001 Aug;76(2):350-7.

72. Dijkhuizen FP, De Vries LD, Mol BW, Brolmann HA, Peters HM, Moret E, et al. Comparison of transvaginal ultrasonography and saline infusion sonography for the detection of intracavitary abnormalities in premenopausal women. Ultrasound Obstet Gynecol. 2000 May;15(5):372-6.

73. Critchley HO, Warner P, Lee AJ, Brechin S, Guise J, Graham B. Evaluation of abnormal uterine bleeding: comparison of three outpatient procedures within cohorts defined by age and menopausal status. Health Technol Assess. 2004 Sep;8(34):iii-iv, 1-139.

74. Valentin L. Use of morphology to characterize and manage common adnexal masses. Best Pract Res Clin Obstet Gynaecol. 2004 Feb;18(1):71-89.

75. Caoili EM, Hertzberg BS, Kliewer MA, DeLong D, Bowie JD. Refractory shadowing from pelvic masses on sonography: a useful diagnostic sign for uterine leiomyomas. AJR Am J Roentgenol. 2000 Jan;174(1):97-101.

76. Dueholm M, Lundorf E, Hansen ES, Ledertoug S, Olesen F. Accuracy of magnetic resonance imaging and transvaginal ultrasonography in the diagnosis, mapping, and measurement of uterine myomas. Am J Obstet Gynecol. 2002 Mar;186(3):409-15.

77. Aviram R, Ochshorn Y, Markovitch O, Fishman A, Cohen I, Altaras MM, et al. Uterine sarcomas versus leiomyomas: gray-scale and Doppler sonographic findings. J Clin Ultrasound. 2005 Jan;33(1):10-3.

78. Szabo I, Szantho A, Csabay L, Csapo Z, Szirmai K, Papp Z. Color Doppler ultrasonography in the differentiation of uterine sarcomas from uterine leiomyomas. Eur $\mathrm{J}$ Gynaecol Oncol. 2002;23(1):29-34.

79. Tanaka YO, Nishida M, Tsunoda H, Okamoto Y, Yoshikawa H. Smooth muscle tumors of uncertain malignant potential and leiomyosarcomas of the uterus: MR findings. J Magn Reson Imaging. 2004 Dec;20(6):998-1007.

80. Botsis D, Kassanos D, Antoniou G, Pyrgiotis E, Karakitsos P, Kalogirou D. Adenomyoma and leiomyoma: differential diagnosis with transvaginal sonography. J Clin Ultrasound. 1998 Jan;26(1):21-5.

81. Huang RT, Chou CY, Chang CH, Yu CH, Huang SC, Yao BL. Differentiation between adenomyoma and leiomyoma with transvaginal ultrasonography. Ultrasound Obstet Gynecol. 1995 Jan;5(1):47-50.

82. Fedele L, Bianchi S, Dorta M, Zanotti F, Brioschi D, Carinelli S. Transvaginal ultrasonography in the differential diagnosis of adenomyoma versus leiomyoma. Am J Obstet Gynecol. 1992 Sep;167(3):603-6.

83. Fedele L, Bianchi S, Dorta M, Arcaini L, Zanotti F, Carinelli S. Transvaginal ultrasonography in the diagnosis of diffuse adenomyosis. Fertil Steril. 1992 Jul;58(1):94-7. 
84. Bazot M, Cortez A, Darai E, Rouger J, Chopier J, Antoine JM, et al.

Ultrasonography compared with magnetic resonance imaging for the diagnosis of adenomyosis: correlation with histopathology. Hum Reprod. 2001 Nov;16(11):2427-33.

85. Reinhold C, Atri M, Mehio A, Zakarian R, Aldis AE, Bret PM. Diffuse uterine adenomyosis: morphologic criteria and diagnostic accuracy of endovaginal sonography. Radiology. 1995 Dec;197(3):609-14.

86. Dueholm M, Lundorf E, Hansen ES, Sorensen JS, Ledertoug S, Olesen F. Magnetic resonance imaging and transvaginal ultrasonography for the diagnosis of adenomyosis. Fertil Steril. 2001 Sep;76(3):588-94.

87. Ascher SM, Arnold LL, Patt RH, Schruefer JJ, Bagley AS, Semelka RC, et al. Adenomyosis: prospective comparison of MR imaging and transvaginal sonography. Radiology. 1994 Mar;190(3):803-6.

88. Vercellini P, Cortesi I, De Giorgi O, Merlo D, Carinelli SG, Crosignani PG. Transvaginal ultrasonography versus uterine needle biopsy in the diagnosis of diffuse adenomyosis. Hum Reprod. 1998 Oct;13(1O):2884-7.

89. Atzori E, Tronci C, Sionis L. Transvaginal ultrasound in the diagnosis of diffuse adenomyosis. Gynecol Obstet Invest. 1996;42(1):39-41.

90. Bazot M, Darai E, Rouger J, Detchev R, Cortez A, Uzan S. Limitations of transvaginal sonography for the diagnosis of adenomyosis, with histopathological correlation. Ultrasound Obstet Gynecol. 2002 Dec;20(6):605-11.

91. Reinhold C, McCarthy S, Bret PM, Mehio A, Atri M, Zakarian R, et al. Diffuse adenomyosis: comparison of endovaginal US and MR imaging with histopathologic correlation. Radiology. 1996 Apr;199(1):151-8.

92. Valentin L. Prospective cross-validation of Doppler ultrasound examination and gray-scale ultrasound imaging for discrimination of benign and malignant pelvic masses. Ultrasound Obstet Gynecol. 1999 Oct;14(4):273-83.

93. Timmerman D, Schwarzler P, Collins WP, Claerhout F, Coenen M, Amant F, et al. Subjective assessment of adnexal masses with the use of ultrasonography: an analysis of interobserver variability and experience. Ultrasound Obstet Gynecol. 1999 Jan;13(1):11-6. 94. Valentin L. Pattern recognition of pelvic masses by gray-scale ultrasound imaging: the contribution of Doppler ultrasound. Ultrasound Obstet Gynecol. 1999 Nov;14(5):338-47. 95. Timmerman D, DePrest J, Bourne T, editors. Ultrasound and Endoscopic Surgery in Obstetrics and Gynaecology. London: Springer-Verlag; 2002.

96. Benacerraf BR, Finkler NJ, Wojciechowski C, Knapp RC. Sonographic accuracy in the diagnosis of ovarian masses. J Reprod Med. 1990 May;35(5):491-5.

97. Fleischer AC, James AE, Jr., Millis JB, Julian C. Differential diagnosis of pelvic masses by gray scale sonography. AJR Am J Roentgenol. 1978 Sep;131(3):469-76.

98. Mais V, Guerriero S, Ajossa S, Angiolucci M, Paoletti AM, Melis GB. Transvaginal ultrasonography in the diagnosis of cystic teratoma. Obstet Gynecol. 1995 Jan;85(1):48-52.

99. Mais V, Guerriero S, Ajossa S, Angiolucci M, Paoletti AM, Melis GB. The efficiency of transvaginal ultrasonography in the diagnosis of endometrioma. Fertil Steril. 1993 Nov;60(5):776-80.

100. Guerriero S, Mais V, Ajossa S, Paoletti AM, Angiolucci M, Melis GB. Transvaginal ultrasonography combined with CA-125 plasma levels in the diagnosis of endometrioma. Fertil Steril. 1996 Feb;65(2):293-8. 
101. Guerriero S, Mais V, Ajossa S, Paoletti AM, Angiolucci M, Labate F, et al. The role of endovaginal ultrasound in differentiating endometriomas from other ovarian cysts. Clin Exp Obstet Gynecol. 1995;22(1):20-2.

102. Kim JS, Woo SK, Suh SJ, Morettin LB. Sonographic diagnosis of paraovarian cysts: value of detecting a separate ipsilateral ovary. AJR Am J Roentgenol. 1995

Jun;164(6):1441-4.

103. Jain KA. Prospective evaluation of adnexal masses with endovaginal gray-scale and duplex and color Doppler US: correlation with pathologic findings. Radiology. 1994 Apr;191(1):63-7.

104. Buy JN, Ghossain MA, Hugol D, Hassen K, Sciot C, Truc JB, et al.

Characterization of adnexal masses: combination of color Doppler and conventional sonography compared with spectral Doppler analysis alone and conventional sonography alone. AJR Am J Roentgenol. 1996 Feb;166(2):385-93.

105. Levine D, Feldstein VA, Babcook CJ, Filly RA. Sonography of ovarian masses: poor sensitivity of resistive index for identifying malignant lesions. AJR Am J Roentgenol. 1994 Jun;162(6):1355-9.

106. Salem S, White LM, Lai J. Doppler sonography of adnexal masses: the predictive value of the pulsatility index in benign and malignant disease. AJR Am J Roentgenol. 1994 Nov;163(5):1147-50.

107. Stein SM, Laifer-Narin S, Johnson MB, Roman LD, Muderspach LI, Tyszka JM, et al. Differentiation of benign and malignant adnexal masses: relative value of gray-scale, color Doppler, and spectral Doppler sonography. AJR Am J Roentgenol. 1995 Feb;164(2):381-6. 108. Barloon TJ, Brown BP, Abu-Yousef MM, Warnock NG. Paraovarian and paratubal cysts: preoperative diagnosis using transabdominal and transvaginal sonography. J Clin Ultrasound. 1996 Mar-Apr;24(3):117-22.

109. Guerriero S, Mallarini G, Ajossa S, Risalvato A, Satta R, Mais V, et al. Transvaginal ultrasound and computed tomography combined with clinical parameters and CA125 determinations in the differential diagnosis of persistent ovarian cysts in premenopausal women. Ultrasound Obstet Gynecol. 1997 May;9(5):339-43.

110. Moore J, Copley S, Morris J, Lindsell D, Golding S, Kennedy S. A systematic review of the accuracy of ultrasound in the diagnosis of endometriosis. Ultrasound Obstet Gynecol. 2002 Dec;20(6):630-4.

111. Lerner JP, Timor-Tritsch IE, Federman A, Abramovich G. Transvaginal ultrasonographic characterization of ovarian masses with an improved, weighted scoring system. Am J Obstet Gynecol. 1994 Jan;170(1 Pt 1):81-5.

112. Jacobs I, Oram D, Fairbanks J, Turner J, Frost C, Grudzinskas JG. A risk of malignancy index incorporating CA 125, ultrasound and menopausal status for the accurate preoperative diagnosis of ovarian cancer. Br J Obstet Gynaecol. 1990 Oct;97(10):922-9.

113. Tailor A, Jurkovic D, Bourne TH, Collins WP, Campbell S. Sonographic prediction of malignancy in adnexal masses using multivariate logistic regression analysis. Ultrasound Obstet Gynecol. 1997 Jul;10(1):41-7.

114. Timmerman D, Bourne TH, Tailor A, Collins WP, Verrelst H, Vandenberghe K, et al. A comparison of methods for preoperative discrimination between malignant and benign adnexal masses: the development of a new logistic regression model. Am J Obstet Gynecol. 1999 Jul;181(1):57-65.

115. Timmerman D, Testa AC, Bourne T, Ferrazzi E, Ameye L, Konstantinovic ML, et al. Logistic regression model to distinguish between the benign and malignant adnexal mass 
before surgery: a multicenter study by the International Ovarian Tumor Analysis Group. J Clin Oncol. 2005 Dec 1;23(34):8794-801.

116. Valentin L. Comparison of Lerner score, Doppler ultrasound examination, and their combination for discrimination between benign and malignant adnexal masses. Ultrasound Obstet Gynecol. 2000 Feb;15(2):143-7.

117. Valentin L, Hagen B, Tingulstad S, Eik-Nes S. Comparison of 'pattern recognition' and logistic regression models for discrimination between benign and malignant pelvic masses: a prospective cross validation. Ultrasound Obstet Gynecol. 2001 Oct;18(4):357-65.

118. Sassone AM, Timor-Tritsch IE, Artner A, Westhoff C, Warren WB. Transvaginal sonographic characterization of ovarian disease: evaluation of a new scoring system to predict ovarian malignancy. Obstet Gynecol. 1991 Jul;78(1):70-6.

119. DePriest PD, Shenson D, Fried A, Hunter JE, Andrews SJ, Gallion HH, et al. A morphology index based on sonographic findings in ovarian cancer. Gynecol Oncol. 1993 Oct;51(1):7-11.

120. Ferrazzi E, Zanetta G, Dordoni D, Berlanda N, Mezzopane R, Lissoni AA. Transvaginal ultrasonographic characterization of ovarian masses: comparison of five scoring systems in a multicenter study. Ultrasound Obstet Gynecol. 1997 Sep;10(3):192-7.

121. Aslam N, Banerjee S, Carr JV, Savvas M, Hooper R, Jurkovic D. Prospective evaluation of logistic regression models for the diagnosis of ovarian cancer. Obstet Gynecol. 2000 Jul;96(1):75-80.

122. Cohen LS, Escobar PF, Scharm C, Glimco B, Fishman DA. Three-dimensional power Doppler ultrasound improves the diagnostic accuracy for ovarian cancer prediction. Gynecol Oncol. 2001 Jul;82(1):40-8.

123. Alcazar JL, Castillo G. Comparison of 2-dimensional and 3-dimensional powerDoppler imaging in complex adnexal masses for the prediction of ovarian cancer. Am J Obstet Gynecol. 2005 Mar;192(3):807-12.

124. Testa AC, Ferrandina G, Fruscella E, Van Holsbeke C, Ferrazzi E, Leone FP, et al. The use of contrasted transvaginal sonography in the diagnosis of gynecologic diseases: a preliminary study. J Ultrasound Med. 2005 Sep;24(9):1267-78.

125. Marret H, Sauget S, Giraudeau B, Brewer M, Ranger-Moore J, Body G, et al. Contrast-enhanced sonography helps in discrimination of benign from malignant adnexal masses. J Ultrasound Med. 2004 Dec;23(12):1629-39; quiz 41-42.

126. Valentin L, Ameye L, Jurkovic D, Metzger U, Lécuru F, Van Huffel S, et al. Which extrauterine pelvic masses are difficult to correctly classify as benign or malignant on the basis of ultrasound findings, and is there a way of making a correct diagnosis? Ultrasound Obstet Gynecol. 2006.

127. Valentin L, Ameye L, Testa A, Lecuru F, Bernard JP, Paladini D, et al. Ultrasound characteristics of different types of adnexal malignancies. Gynecol Oncol. 2005 Dec 27.

128. deSouza NM, O'Neill R, McIndoe GA, Dina R, Soutter WP. Borderline tumors of the ovary: CT and MRI features and tumor markers in differentiation from stage I disease. AJR Am J Roentgenol. 2005 Mar;184(3):999-1003.

129. Buy JN, Ghossain MA, Sciot C, Bazot M, Guinet C, Prevot S, et al. Epithelial tumors of the ovary: CT findings and correlation with US. Radiology. 1991 Mar;178(3):811-8. 130. Thurnher S, Hodler J, Baer S, Marincek B, von Schulthess GK. Gadolinium-DOTA enhanced MR imaging of adnexal tumors. J Comput Assist Tomogr. 1990 Nov-Dec;14(6):93949. 
131. Scoutt LM, McCarthy SM, Lange R, Bourque A, Schwartz PE. MR evaluation of clinically suspected adnexal masses. J Comput Assist Tomogr. 1994 Jul-Aug;18(4):609-18.

132. Stevens SK, Hricak H, Stern JL. Ovarian lesions: detection and characterization with gadolinium-enhanced MR imaging at 1.5 T. Radiology. 1991 Nov;181(2):481-8.

133. Hricak H, Chen M, Coakley FV, Kinkel K, Yu KK, Sica G, et al. Complex adnexal masses: detection and characterization with MR imaging--multivariate analysis. Radiology. 2000 Jan;214(1):39-46.

134. Sohaib SA, Sahdev A, Van Trappen P, Jacobs IJ, Reznek RH. Characterization of adnexal mass lesions on MR imaging. AJR Am J Roentgenol. 2003 May;180(5):1297-304.

135. Yamashita Y, Hatanaka Y, Torashima M, Takahashi M, Miyazaki K, Okamura H. Characterization of sonographically indeterminate ovarian tumors with MR imaging. A logistic regression analysis. Acta Radiol. 1997 Jul;38(4 Pt 1):572-7.

136. Saini A, Dina R, McIndoe GA, Soutter WP, Gishen P, deSouza NM.

Characterization of adnexal masses with MRI. AJR Am J Roentgenol. 2005 Mar;184(3):1004-9.

137. Kinkel K, Lu Y, Mehdizade A, Pelte MF, Hricak H. Indeterminate ovarian mass at

US: incremental value of second imaging test for characterization--meta-analysis and Bayesian analysis. Radiology. 2005 Jul;236(1):85-94.

138. Sohaib SA, Mills TD, Sahdev A, Webb JA, Vantrappen PO, Jacobs IJ, et al. The role of magnetic resonance imaging and ultrasound in patients with adnexal masses. Clin Radiol. 2005 Mar;60(3):340-8.

139. Timor-Tritsch IE, Lerner JP, Monteagudo A, Murphy KE, Heller DS. Transvaginal sonographic markers of tubal inflammatory disease. Ultrasound Obstet Gynecol. 1998 Jul;12(1):56-66.

140. Molander P, Sjoberg J, Paavonen J, Cacciatore B. Transvaginal power Doppler findings in laparoscopically proven acute pelvic inflammatory disease. Ultrasound Obstet Gynecol. 2001 Mar;17(3):233-8.

141. Cacciatore B, Leminen A, Ingman-Friberg S, Ylostalo P, Paavonen J. Transvaginal sonographic findings in ambulatory patients with suspected pelvic inflammatory disease. Obstet Gynecol. 1992 Dec;80(6):912-6.

142. Boardman LA, Peipert JF, Brody JM, Cooper AS, Sung J. Endovaginal sonography for the diagnosis of upper genital tract infection. Obstet Gynecol. 1997 Jul;90(1):54-7.

143. Gaitan H, Angel E, Diaz R, Parada A, Sanchez L, Vargas C. Accuracy of five different diagnostic techniques in mild-to-moderate pelvic inflammatory disease. Infect Dis Obstet Gynecol. 2002;10(4):171-80.

144. Tukeva TA, Aronen HJ, Karjalainen PT, Molander P, Paavonen T, Paavonen J. MR imaging in pelvic inflammatory disease: comparison with laparoscopy and US. Radiology. 1999 Jan;210(1):209-16.

145. Stark JE, Siegel MJ. Ovarian torsion in prepubertal and pubertal girls: sonographic findings. AJR Am J Roentgenol. 1994 Dec;163(6):1479-82.

146. Graif M, Shalev J, Strauss S, Engelberg S, Mashiach S, Itzchak Y. Torsion of the ovary: sonographic features. AJR Am J Roentgenol. 1984 Dec;143(6):1331-4.

147. Varras M, Tsikini A, Polyzos D, Samara C, Hadjopoulos G, Akrivis C. Uterine adnexal torsion: pathologic and gray-scale ultrasonographic findings. Clin Exp Obstet Gynecol. 2004;31(1):34-8.

148. Albayram F, Hamper UM. Ovarian and adnexal torsion: spectrum of sonographic findings with pathologic correlation. J Ultrasound Med. 2001 Oct;20(10):1083-9. 
149. Shalev J, Mashiach R, Bar-Hava I, Girtler O, Bar J, Dicker D, et al. Subtorsion of the ovary: sonographic features and clinical management. J Ultrasound Med. 2001 Aug;20(8):849-54; quiz 56.

150. Vijayaraghavan SB. Sonographic whirlpool sign in ovarian torsion. J Ultrasound Med. 2004 Dec;23(12):1643-9; quiz 50-1.

151. Rha SE, Byun JY, Jung SE, Jung JI, Choi BG, Kim BS, et al. CT and MR imaging features of adnexal torsion. Radiographics. 2002 Mar-Apr;22(2):283-94.

152. Kimura I, Togashi K, Kawakami S, Takakura K, Mori T, Konishi J. Ovarian torsion: CT and MR imaging appearances. Radiology. 1994 Feb;190(2):337-41.

153. Ben-Ami M, Perlitz Y, Haddad S. The effectiveness of spectral and color Doppler in predicting ovarian torsion. A prospective study. Eur J Obstet Gynecol Reprod Biol. 2002 Aug 5;104(1):64-6.

154. Howard FM. The role of laparoscopy in chronic pelvic pain: promise and pitfalls. Obstet Gynecol Surv. 1993 Jun;48(6):357-87.

155. Porpora MG, Gomel V. The role of laparoscopy in the management of pelvic pain in women of reproductive age. Fertil Steril. 1997 Nov;68(5):765-79.

156. Okaro E, Condous G, Khalid A, Timmerman D, Ameye L, Huffel SV, et al. The use of ultrasound-based 'soft markers' for the prediction of pelvic pathology in women with chronic pelvic pain-can we reduce the need for laparoscopy? Bjog. 2006 Mar;113(3):251-6.

157. Chapron C, Dubuisson JB, Pansini V, Vieira M, Fauconnier A, Barakat H, et al. Routine clinical examination is not sufficient for diagnosing and locating deeply infiltrating endometriosis. J Am Assoc Gynecol Laparosc. 2002 May;9(2):115-9.

158. Bazot M, Darai E, Hourani R, Thomassin I, Cortez A, Uzan S, et al. Deep pelvic endometriosis: MR imaging for diagnosis and prediction of extension of disease. Radiology. 2004 Aug;232(2):379-89.

159. Bazot M, Detchev R, Cortez A, Amouyal P, Uzan S, Darai E. Transvaginal sonography and rectal endoscopic sonography for the assessment of pelvic endometriosis: a preliminary comparison. Hum Reprod. 2003 Aug;18(8):1686-92.

160. Bazot M, Thomassin I, Hourani R, Cortez A, Darai E. Diagnostic accuracy of transvaginal sonography for deep pelvic endometriosis. Ultrasound Obstet Gynecol. 2004 Aug;24(2):180-5.

161. Delpy R, Barthet M, Gasmi M, Berdah S, Shojai R, Desjeux A, et al. Value of endorectal ultrasonography for diagnosing rectovaginal septal endometriosis infiltrating the rectum. Endoscopy. 2005 Apr;37(4):357-61.

162. Abrao MS, Neme RM, Averbach M, Petta CA, Aldrighi JM. Rectal endoscopic ultrasound with a radial probe in the assessment of rectovaginal endometriosis. J Am Assoc Gynecol Laparosc. 2004 Feb;11(1):50-4.

163. Dessole S, Farina M, Rubattu G, Cosmi E, Ambrosini G, Nardelli GB.

Sonovaginography is a new technique for assessing rectovaginal endometriosis. Fertil Steril. 2003 Apr;79(4):1023-7.

164. Chapron C, Vieira M, Chopin N, Balleyguier C, Barakat H, Dumontier I, et al. Accuracy of rectal endoscopic ultrasonography and magnetic resonance imaging in the diagnosis of rectal involvement for patients presenting with deeply infiltrating endometriosis. Ultrasound Obstet Gynecol. 2004 Aug;24(2):175-9.

165. Fedele L, Bianchi S, Portuese A, Borruto F, Dorta M. Transrectal ultrasonography in the assessment of rectovaginal endometriosis. Obstet Gynecol. 1998 Mar;91(3):444-8. 
166. Kataoka ML, Togashi K, Yamaoka T, Koyama T, Ueda H, Kobayashi H, et al. Posterior cul-de-sac obliteration associated with endometriosis: MR imaging evaluation. Radiology. 2005 Mar;234(3):815-23.

167. Takeuchi H, Kuwatsuru R, Kitade M, Sakurai A, Kikuchi I, Shimanuki H, et al. A novel technique using magnetic resonance imaging jelly for evaluation of rectovaginal endometriosis. Fertil Steril. 2005 Feb;83(2):442-7.

168. Exacoustos C, Zupi E, Carusotti C, Rinaldo D, Marconi D, Lanzi G, et al. Staging of pelvic endometriosis: role of sonographic appearance in determining extension of disease and modulating surgical approach. J Am Assoc Gynecol Laparosc. 2003 Aug;10(3):378-82.

169. Guerriero S, Ajossa S, Lai MP, Mais V, Paoletti AM, Melis GB. Transvaginal ultrasonography in the diagnosis of pelvic adhesions. Hum Reprod. 1997 Dec;12(12):2649-53. 170. Ubaldi F, Wisanto A, Camus M, Tournaye H, Clasen K, Devroey P. The role of transvaginal ultrasonography in the detection of pelvic pathologies in the infertility workup. Hum Reprod. 1998 Feb;13(2):330-3.

171. Seow KM, Lin YH, Hsieh BC, Huang LW, Pan HS, Chang JZ, et al. Transvaginal three-dimensional ultrasonography combined with serum CA 125 level for the diagnosis of pelvic adhesions before laparoscopic surgery. J Am Assoc Gynecol Laparosc. 2003 Aug;10(3):320-6. 172. Katayama M, Masui T, Kobayashi S, Ito T, Sakahara H, Nozaki A, et al. Evaluation of pelvic adhesions using multiphase and multislice MR imaging with kinematic display. AJR Am J Roentgenol. 2001 Jul;177(1):107-10. 


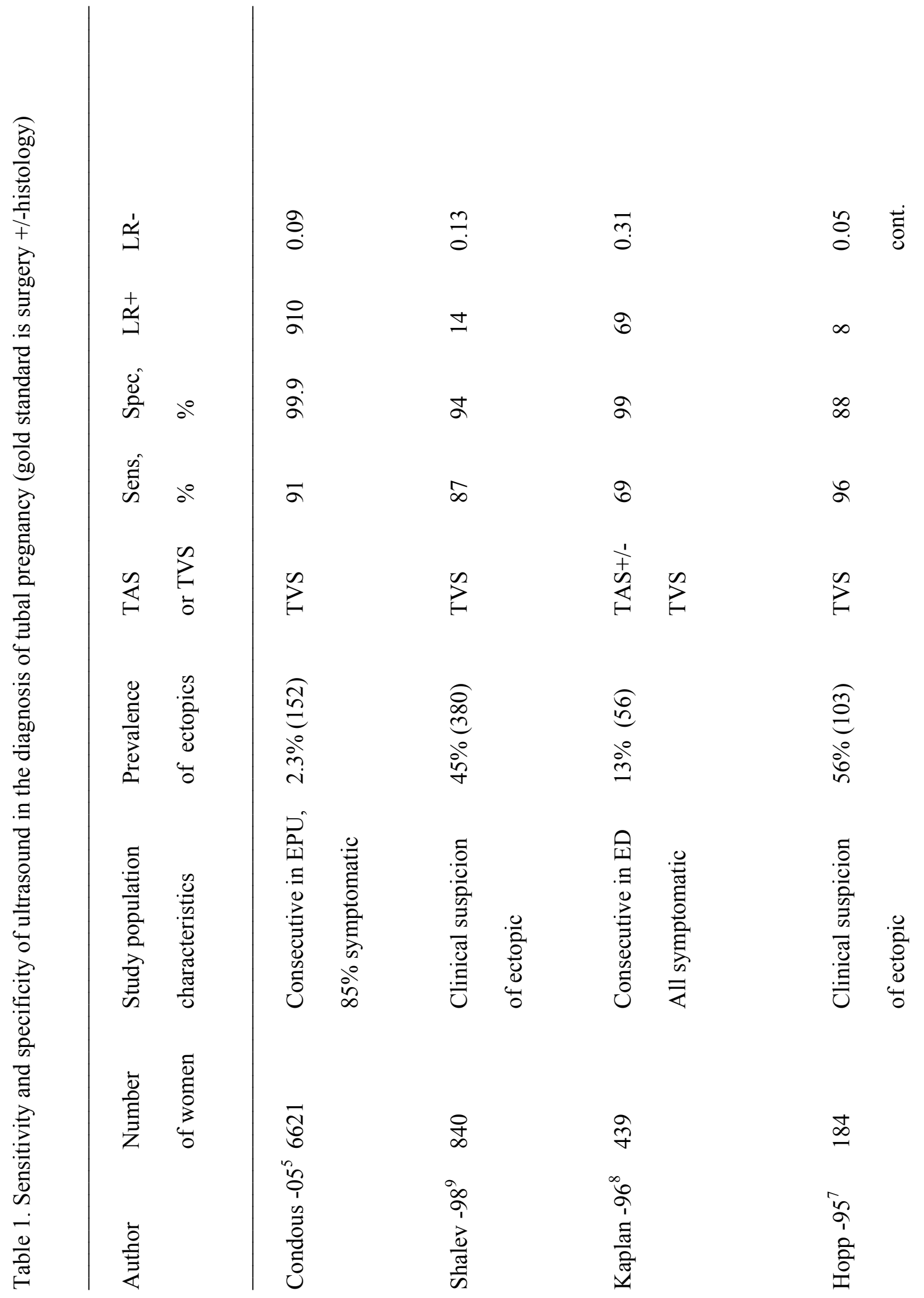




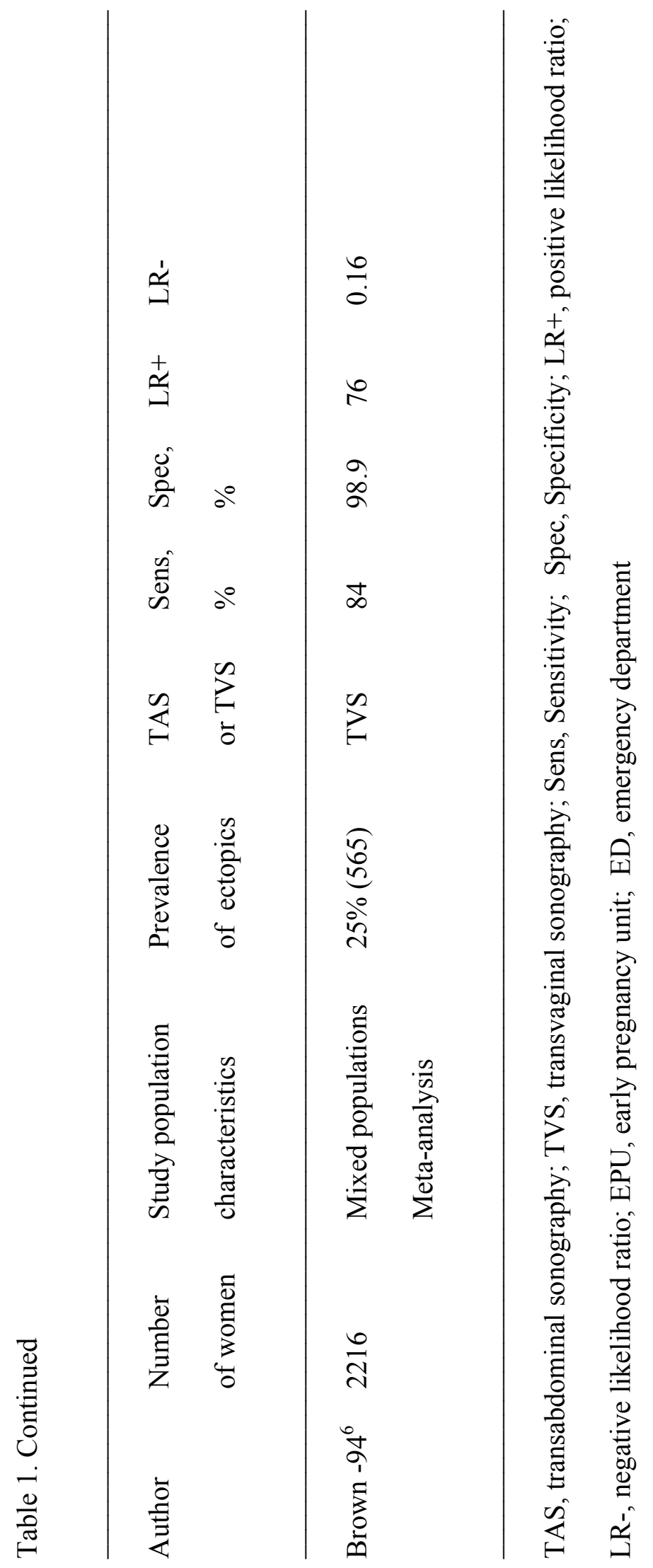




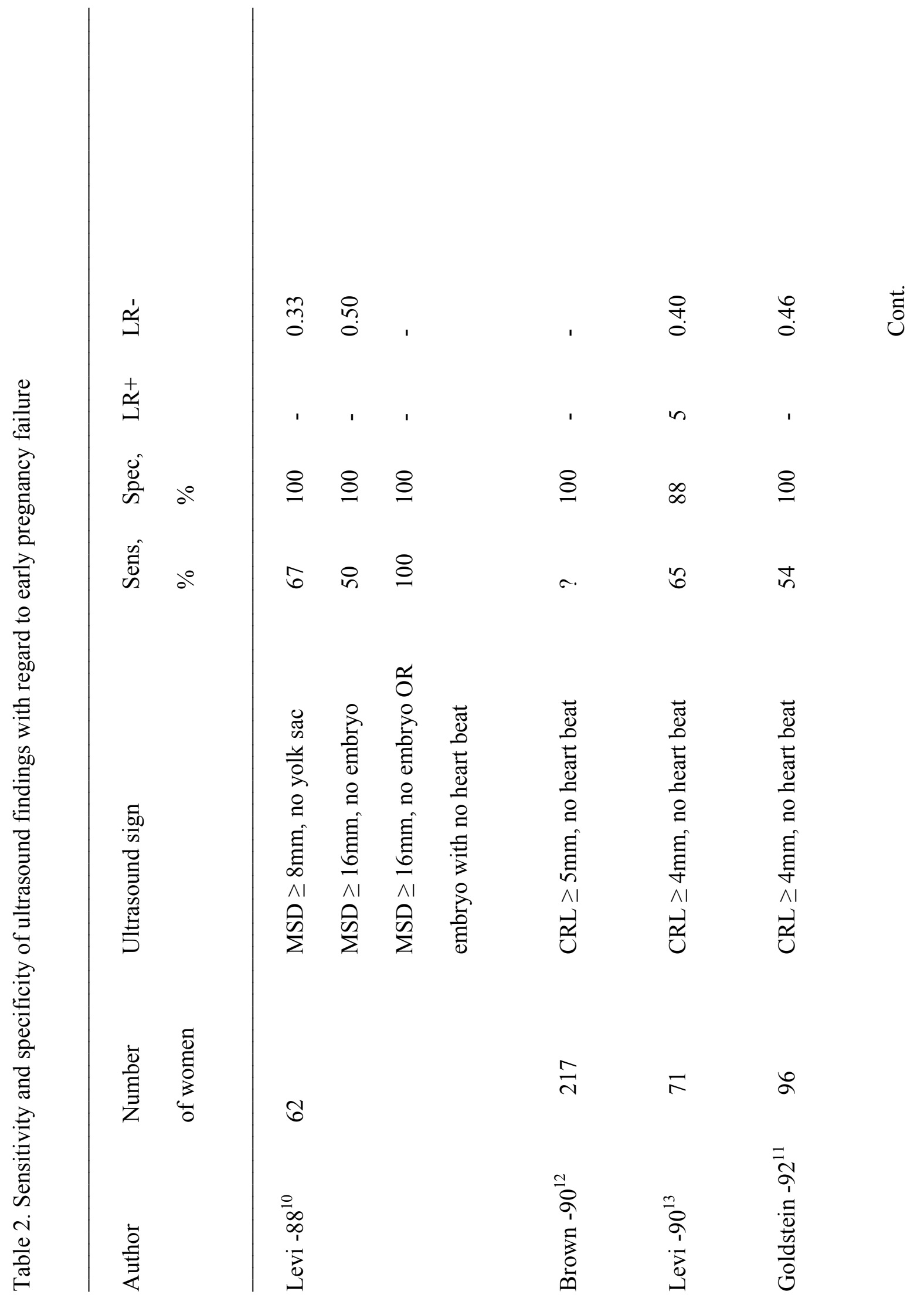




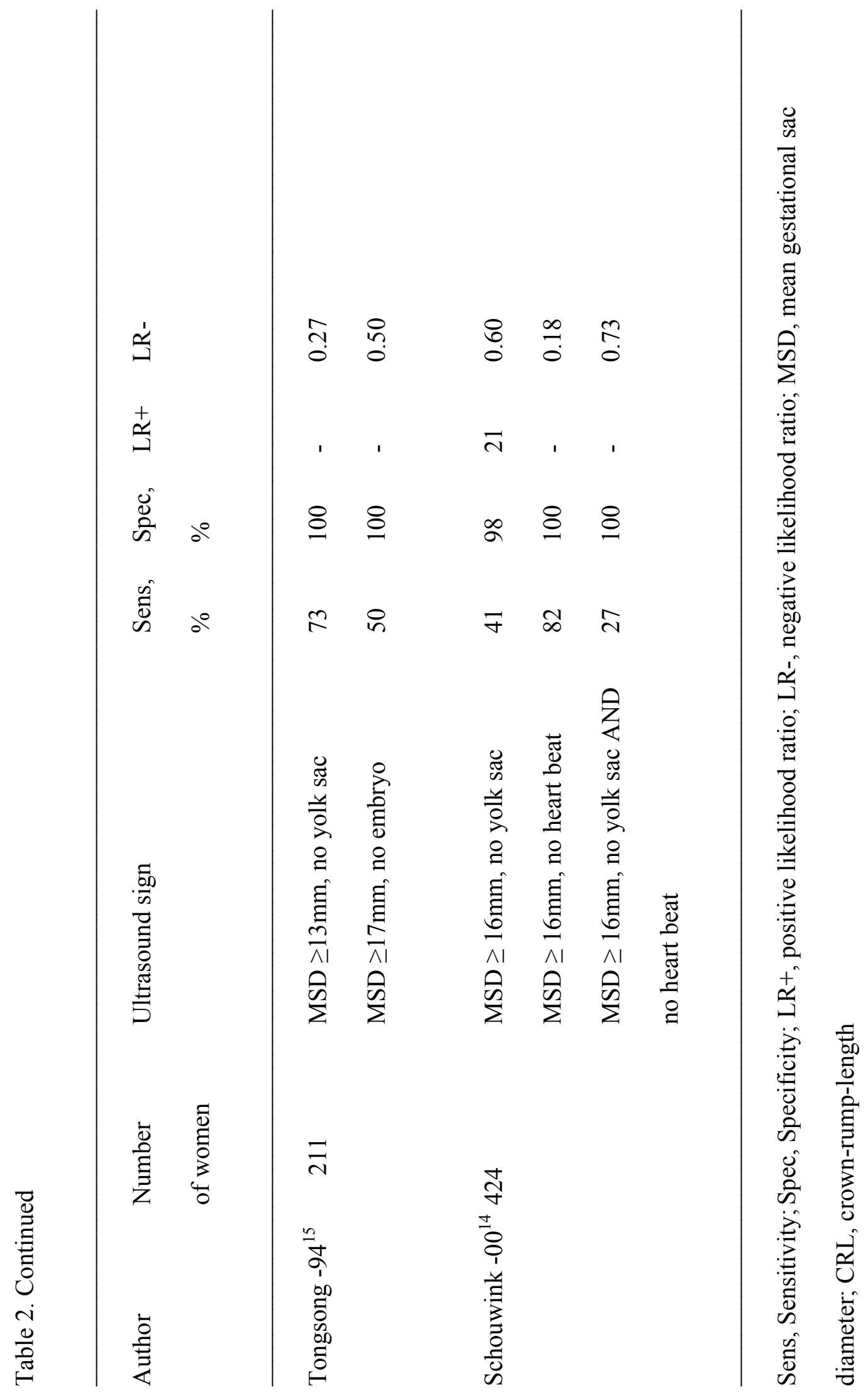




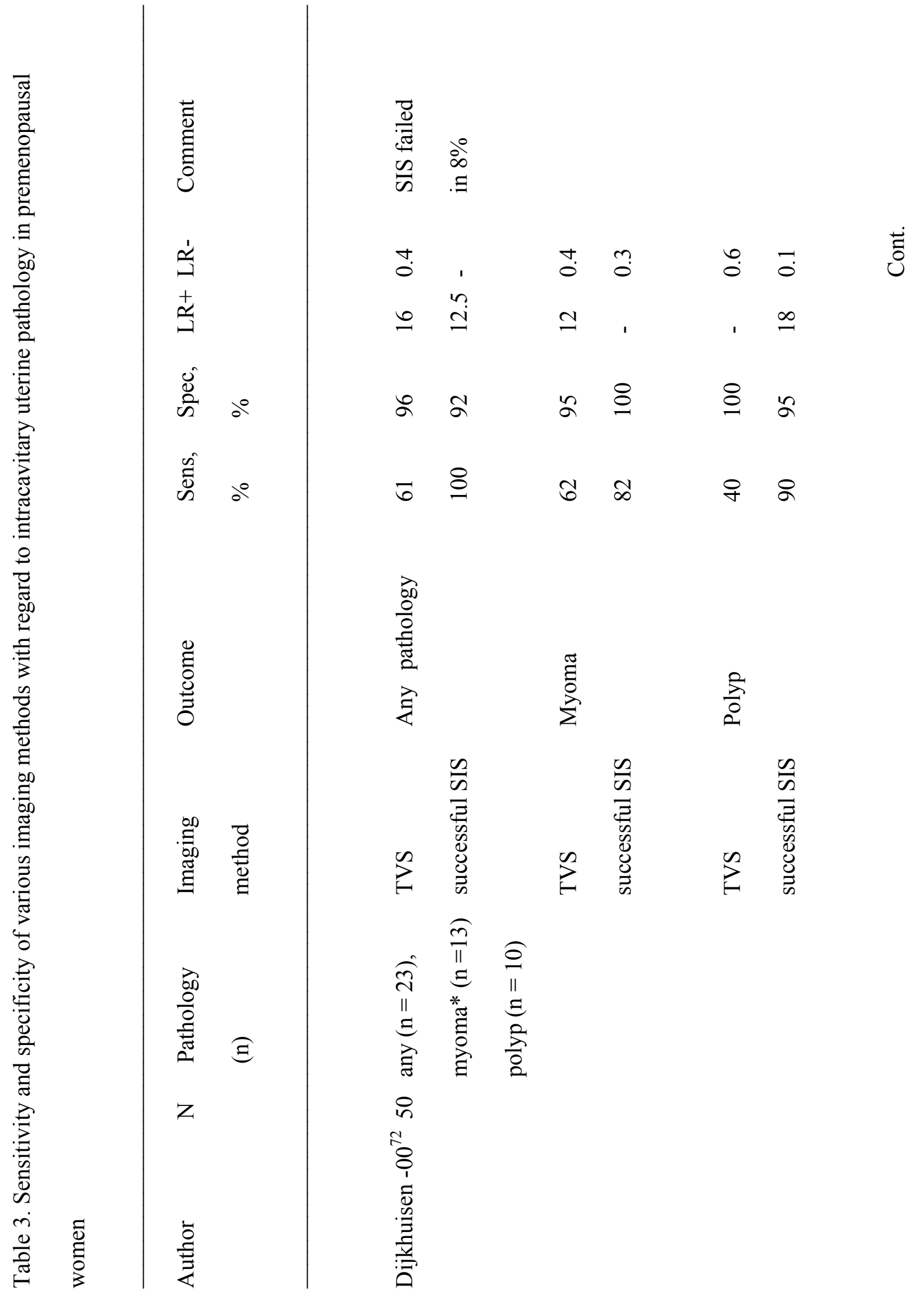




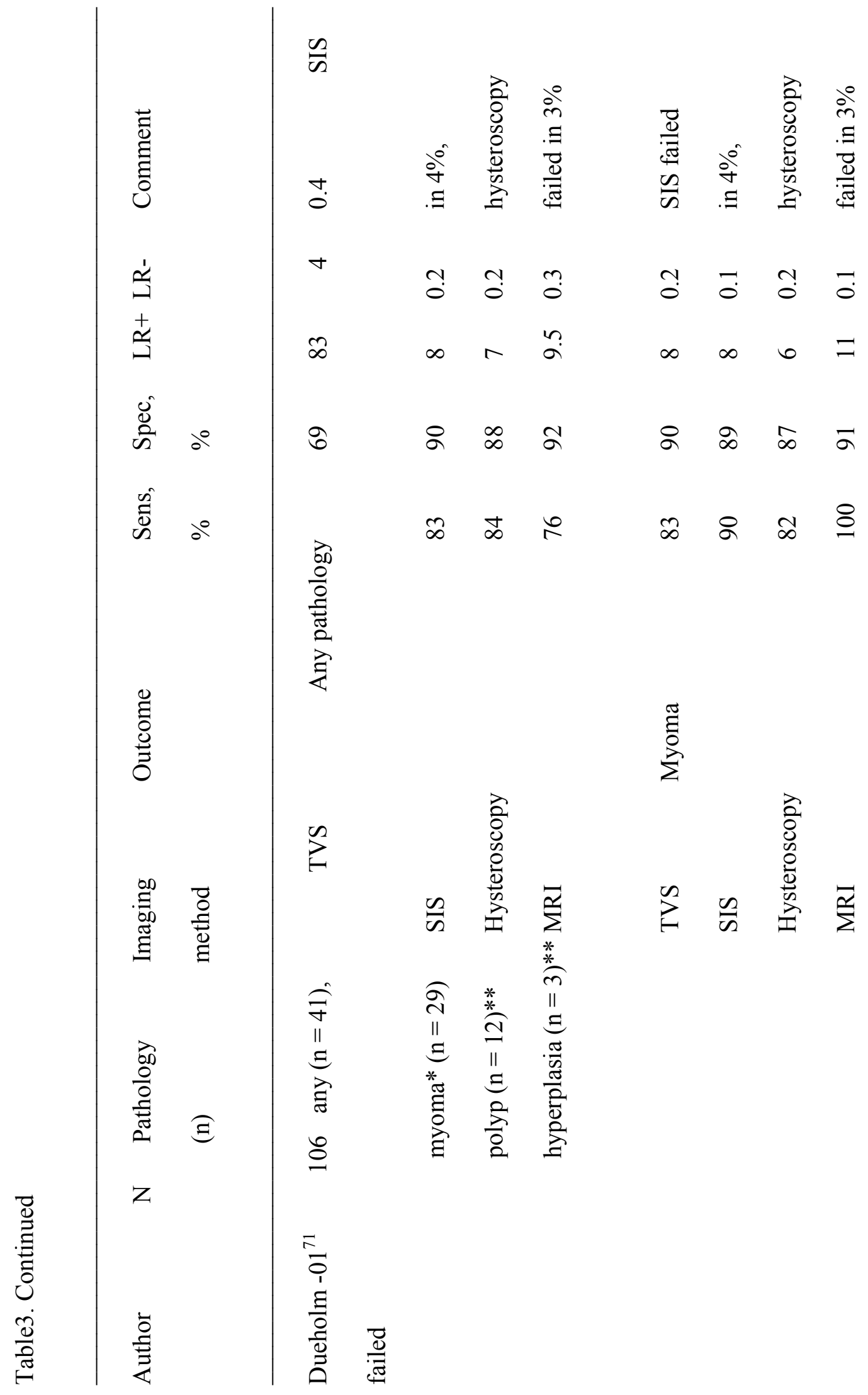




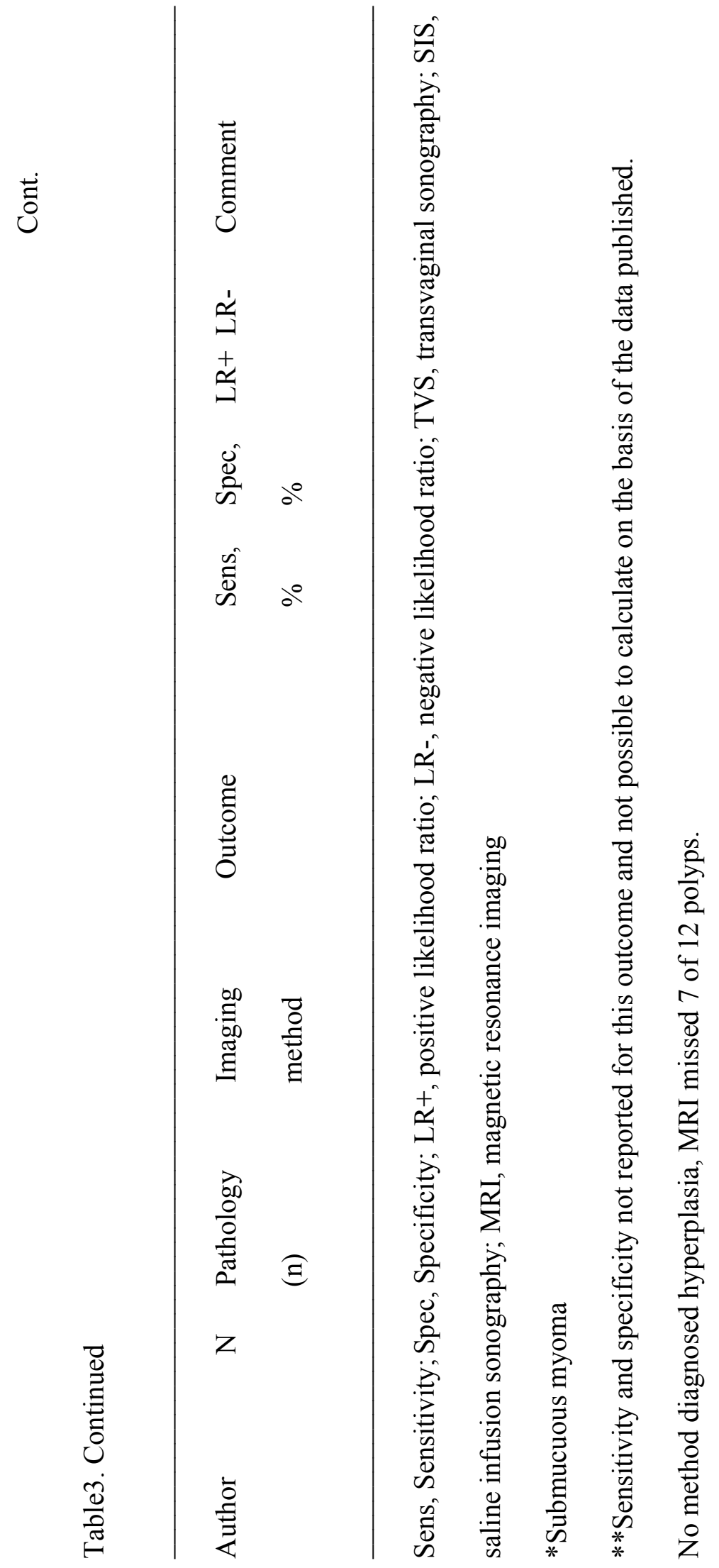




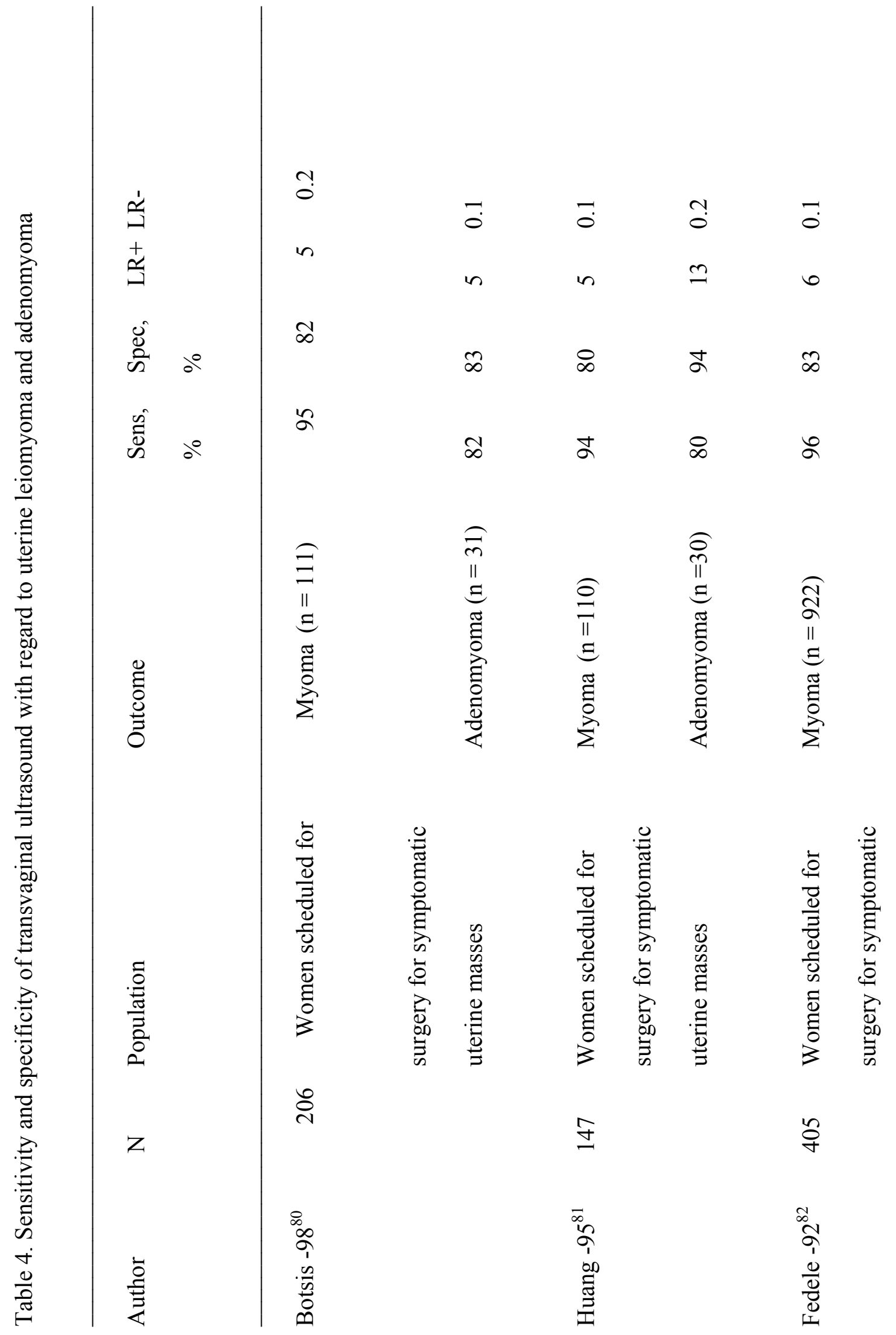




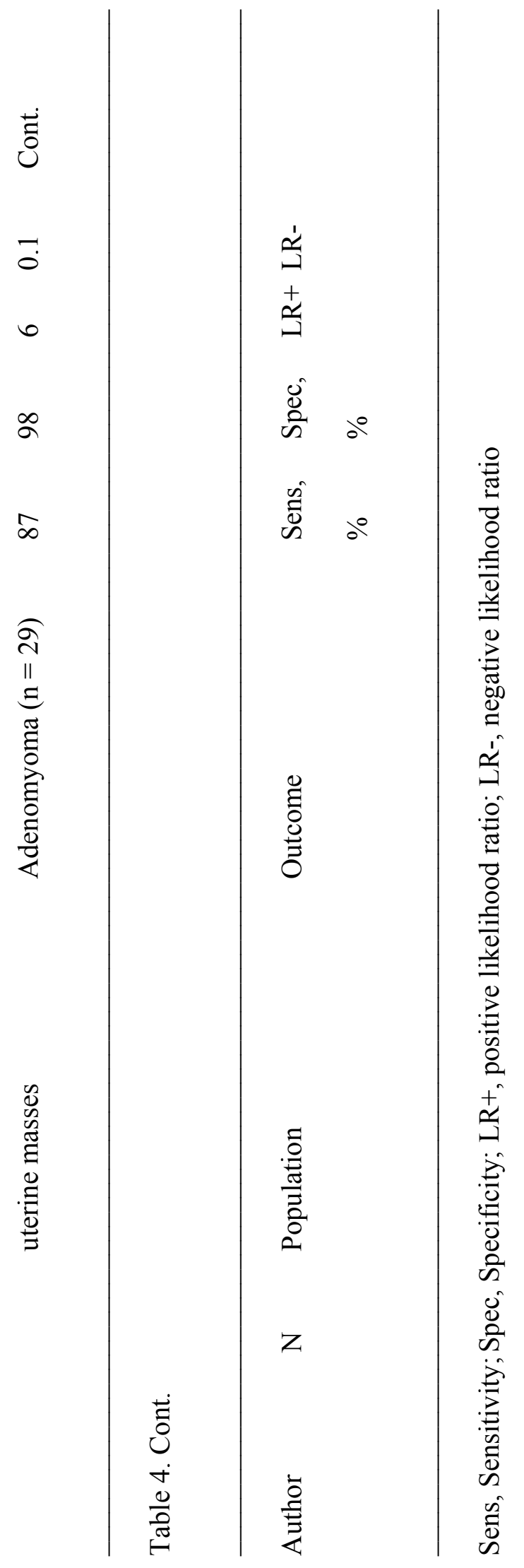




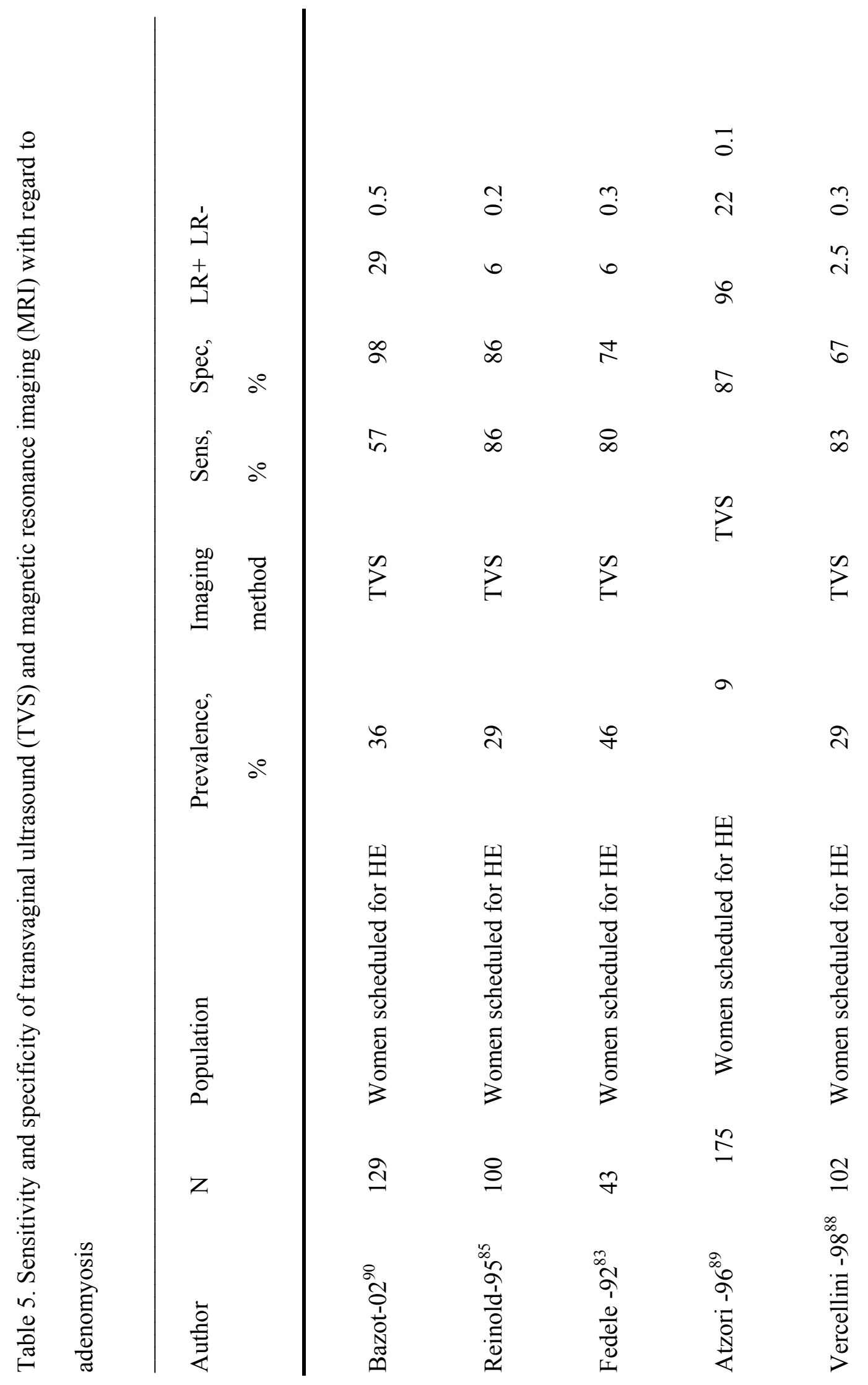




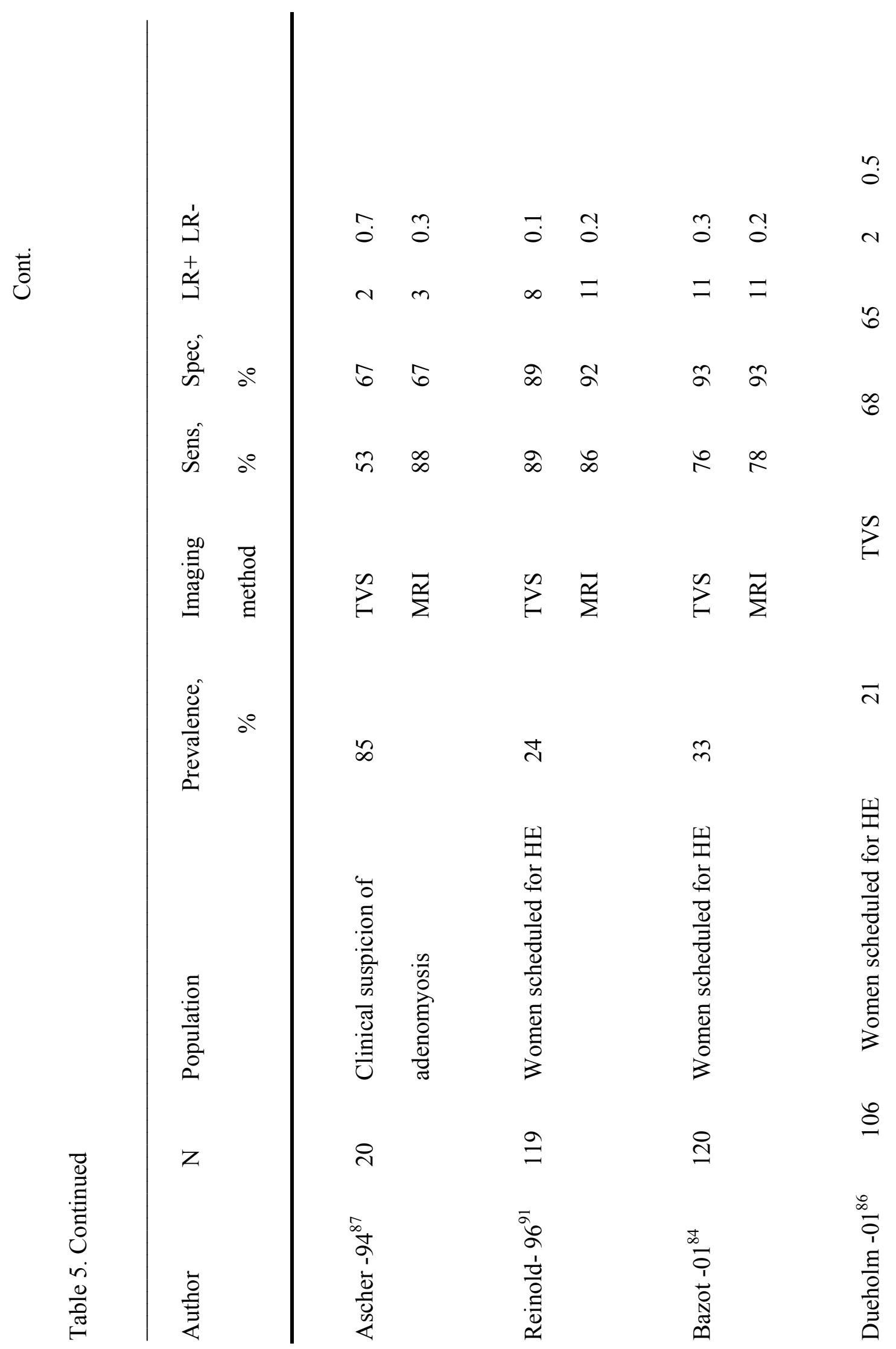




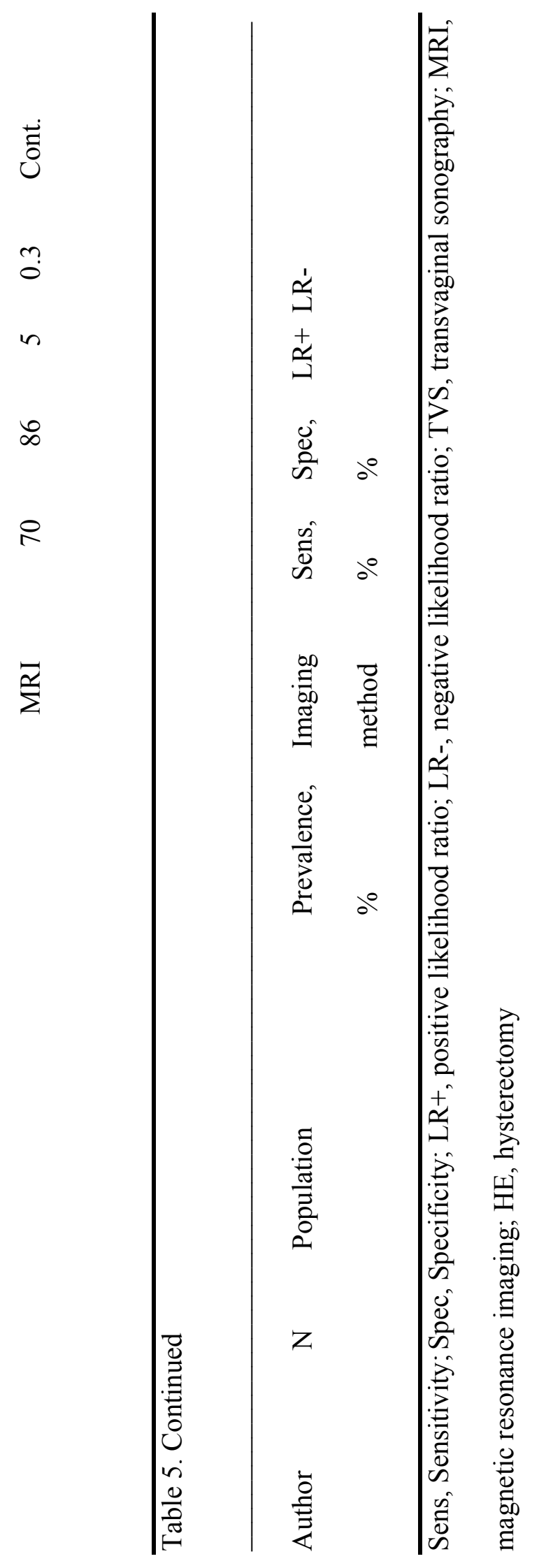


Table 6. Sensitivity and specificity of subjective evaluation of the grey scale ultrasound image ('pattern recognition') for discrimination between benign and malignant pelvic masses and for making a specific diagnosis

My own series [94]

Diagnosis

Malignancy

Dermoid cyst

Endometrioma

$92(24 / 26)$

$97(143 / 147)$

Corpus luteum cyst

Hydro-, pyo-, or

$100(8 / 8)$

$100(165 / 165)$

hemato-salpinx

Paraovarian or

$83(5 / 6)^{a}$

$99(166 / 167)$

paratubal cyst

Peritoneal pseudocyst $100(3 / 3)$

$10-97$

not reported
Other series [96 - 109]

Sensitivity Specificity

\footnotetext{
paratubal cyst
}

not reported

not reported

$99(169 / 170)$

Peritoneal pseudocyst $100(3 / 3)$

Ovarian fibroma or $56(5 / 9)$

$100(164 / 164)$

not reported

not reported 
fibrothecoma

Myoma

$86(6 / 7)$

$99(165 / 166)$

93

98

Cont.

Table 1. Cont.

My own series [94]

Diagnosis

Sensitivity

Specificity

Other series [96 - 109]

Sensitivity Specificity

Abscess

$33(1 / 3)$

$99(169 / 170)$

not reported

not reported

*All malignancies missed were borderline tumors; \# No specific diagnosis was suggested in the two cases missed (false-negatives). The two cysts were seen to contain sonolucent fluid, a few septae, and minor solid components not resembling fat or hair; a No specific diagnosis was suggested in the case missed (false-negative) 


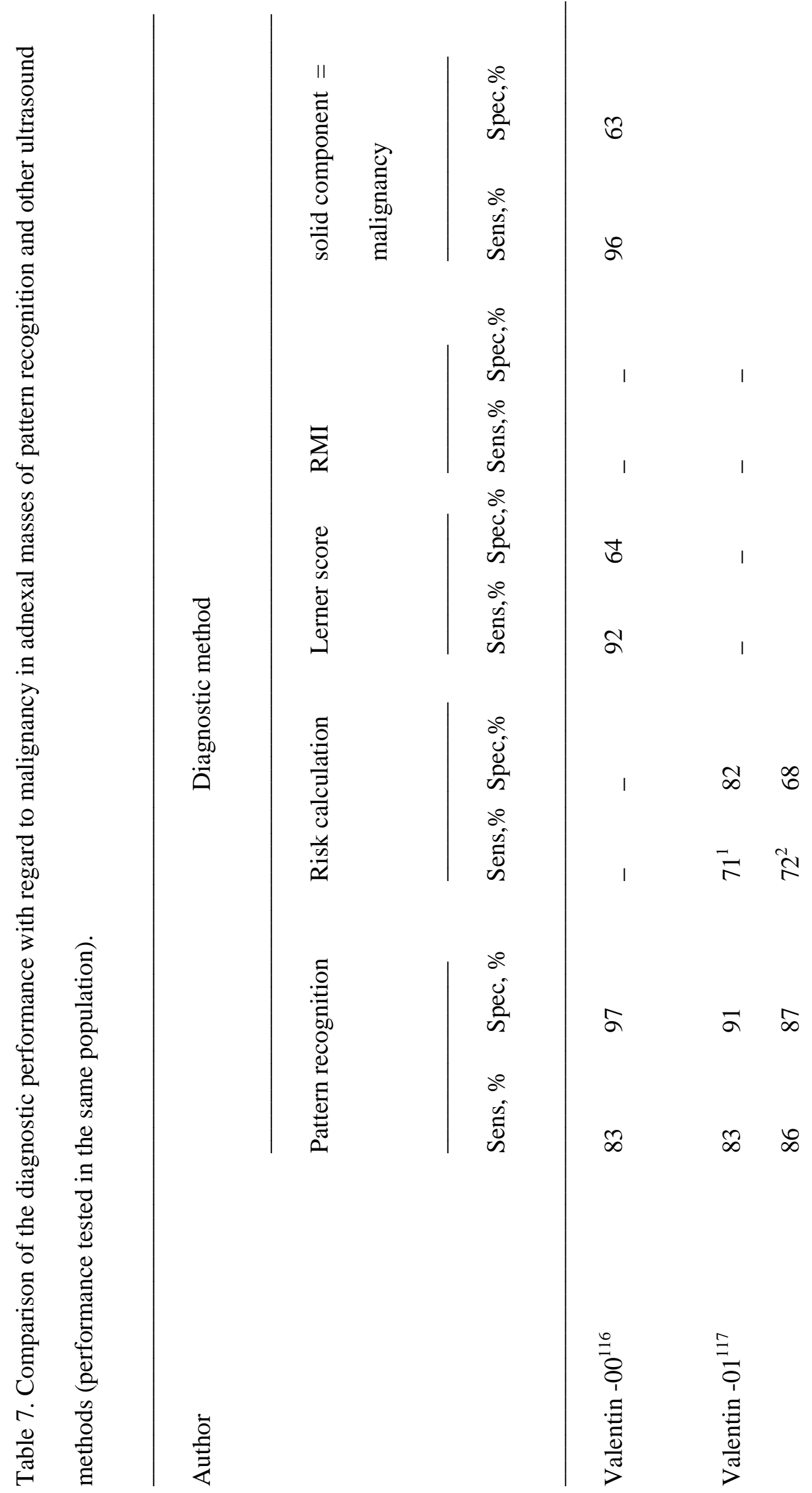




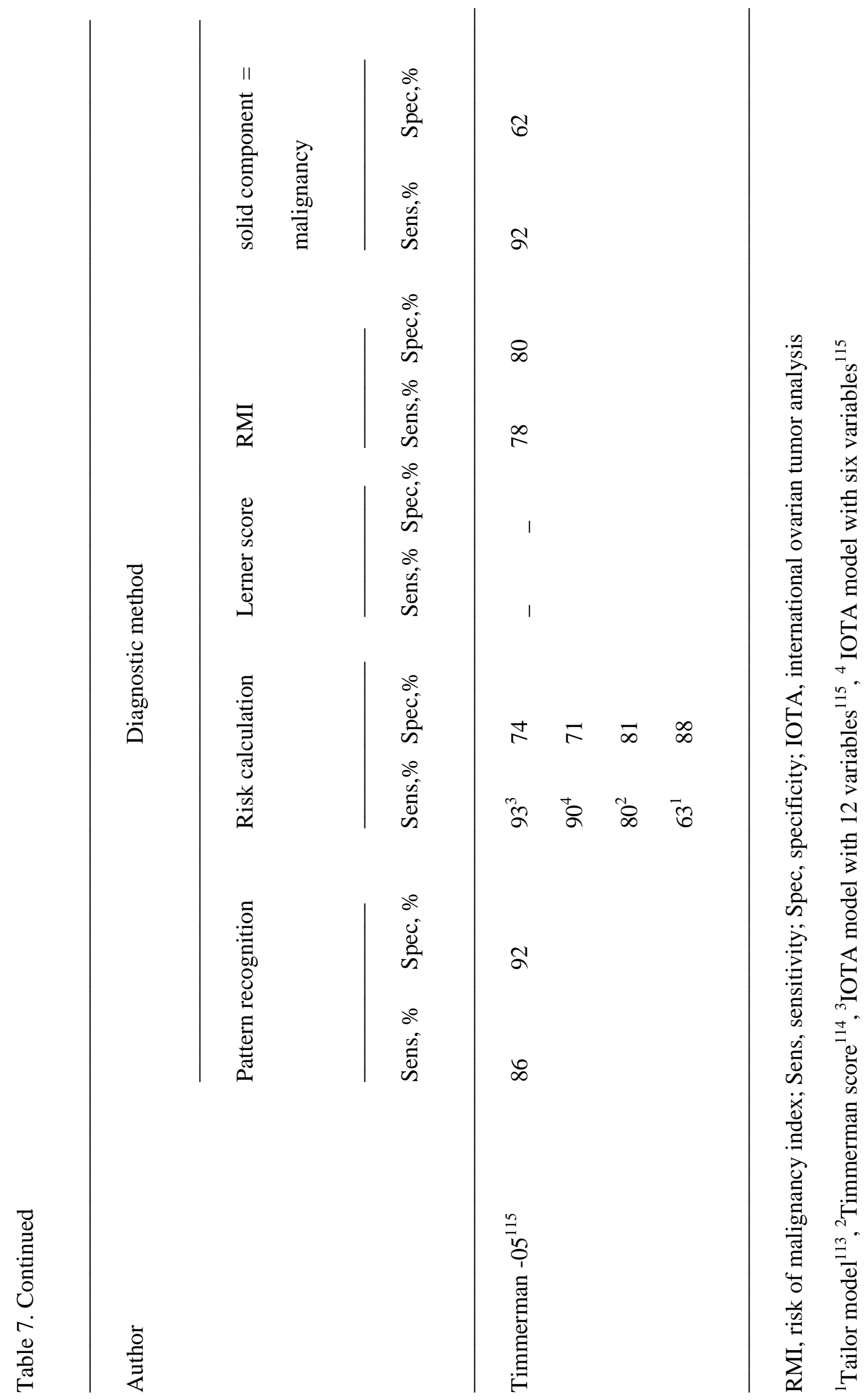




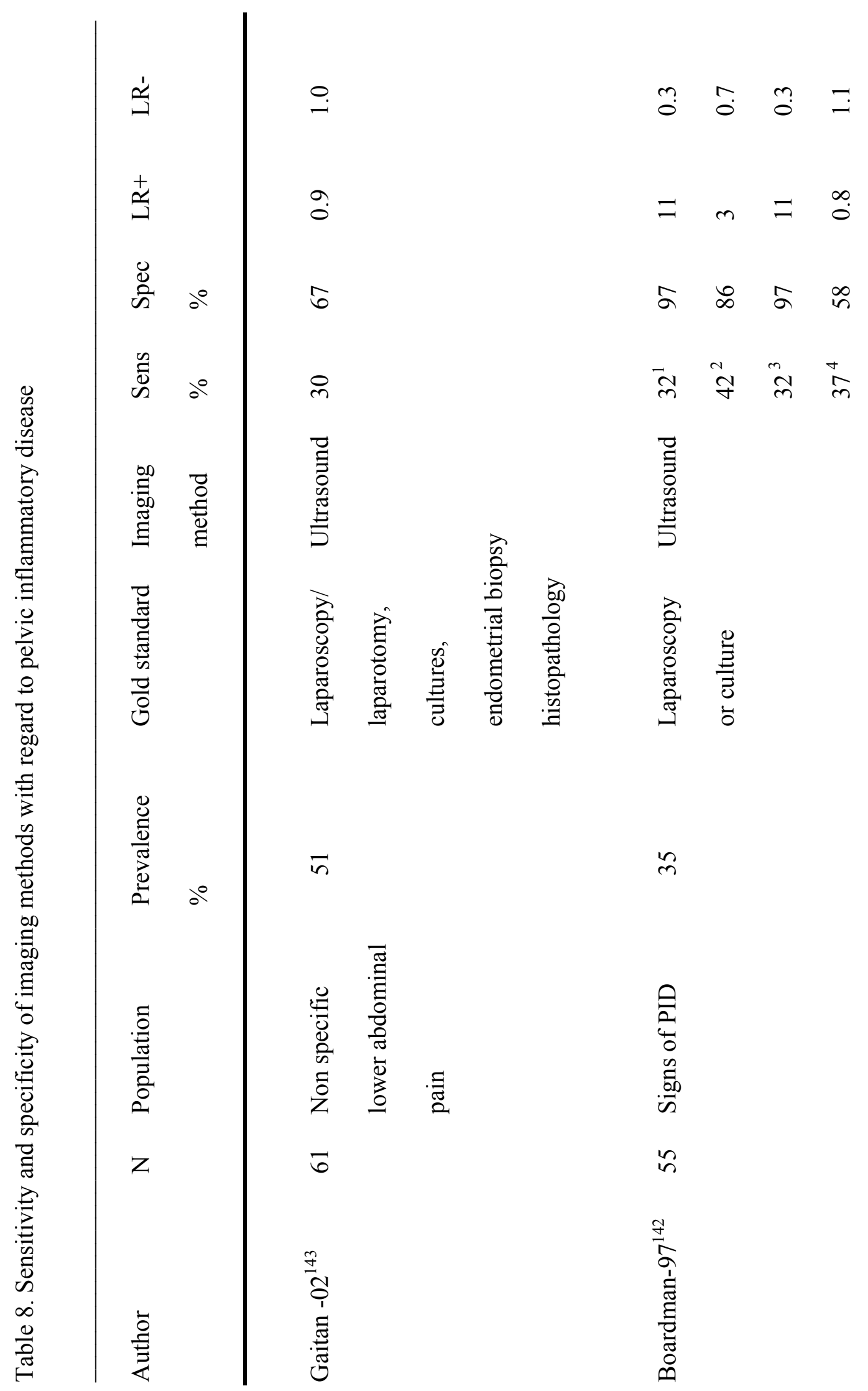




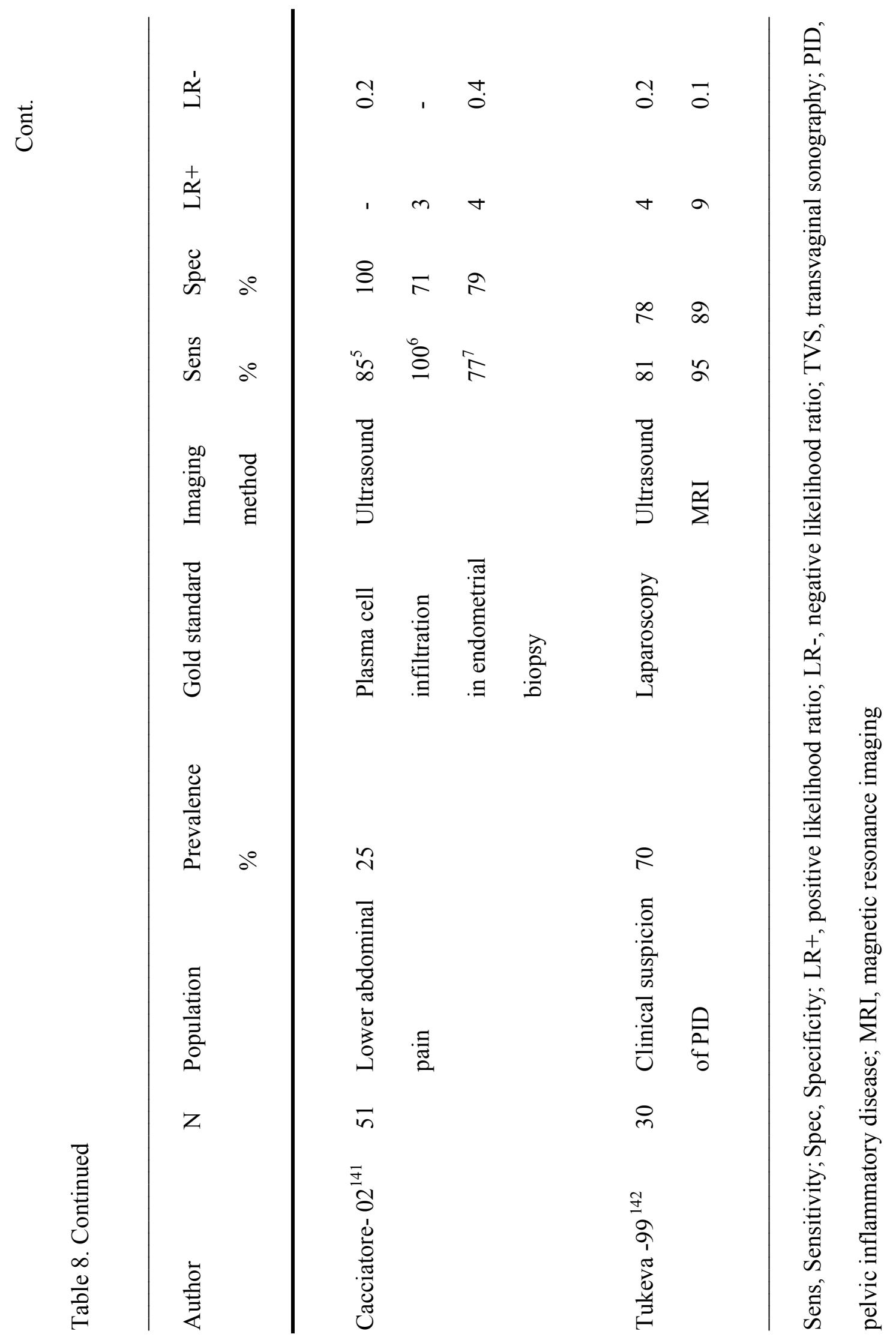




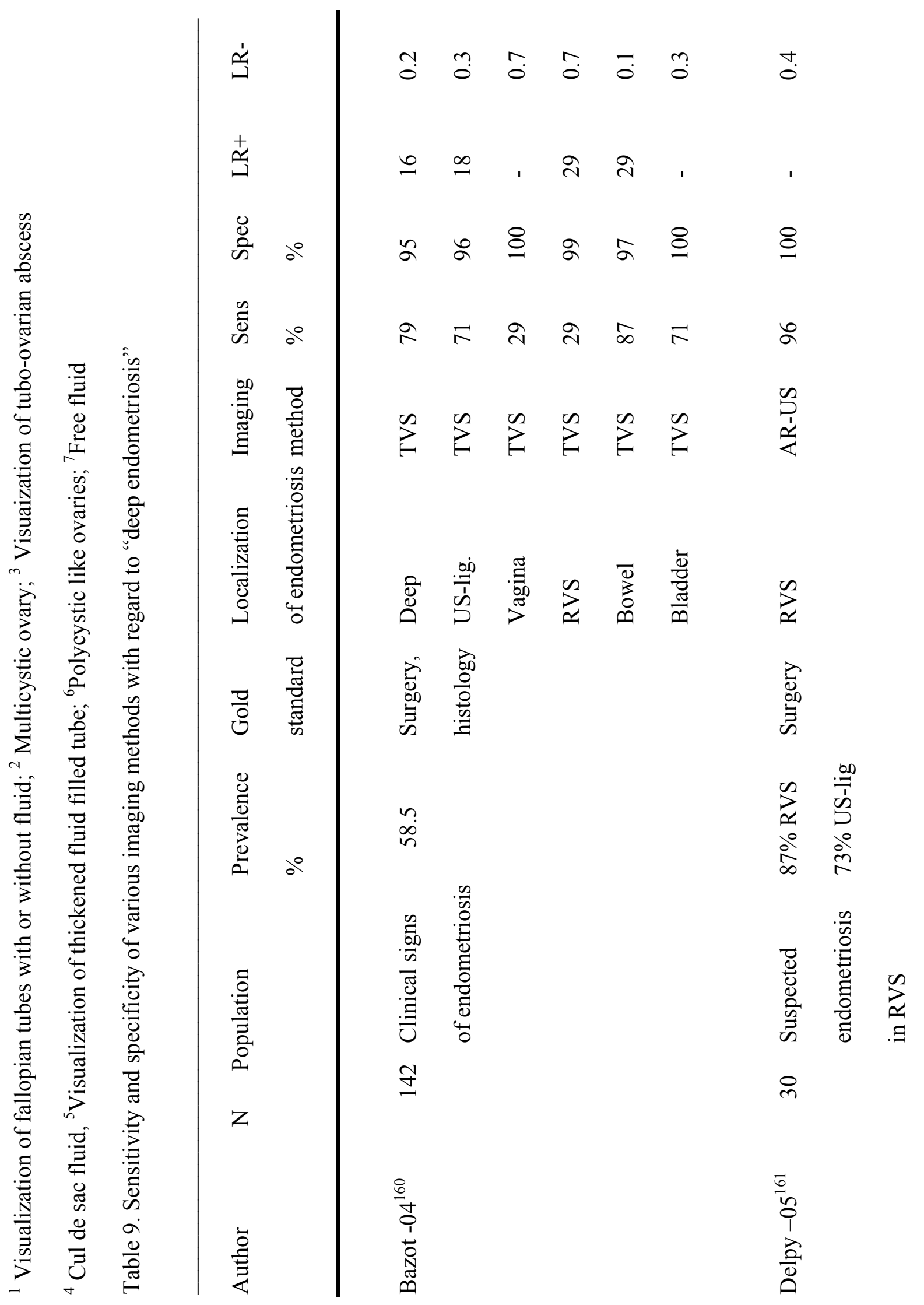




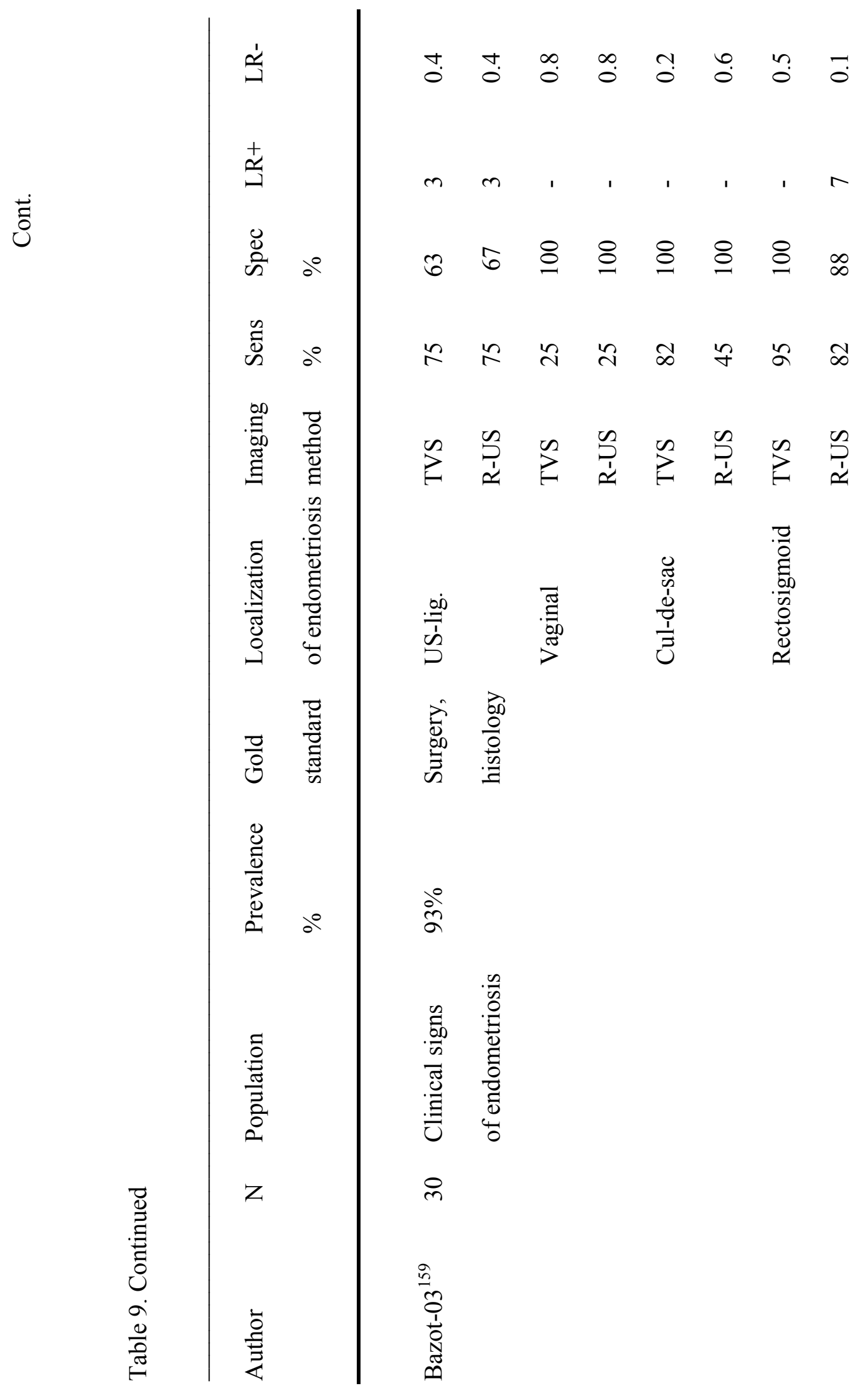




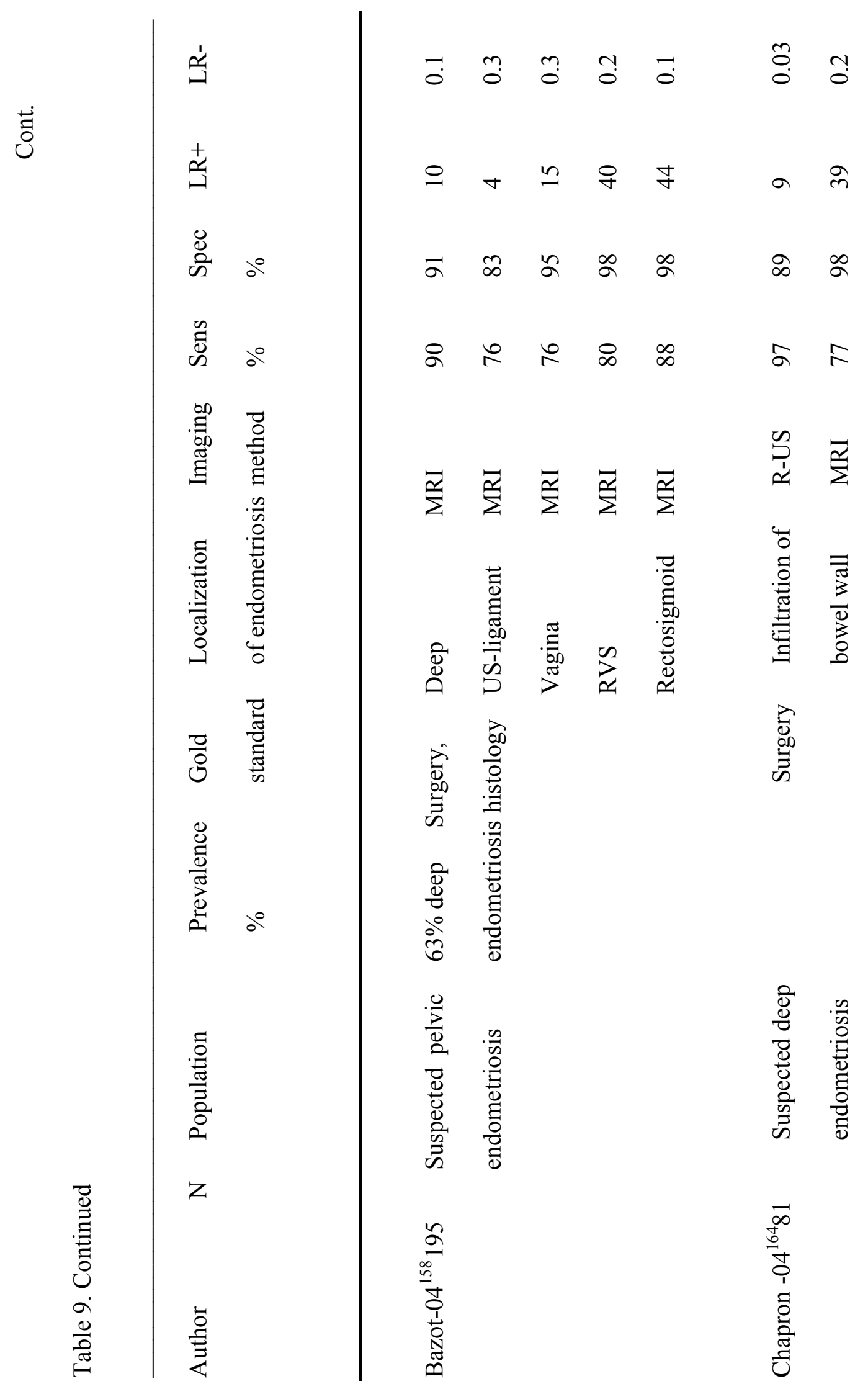




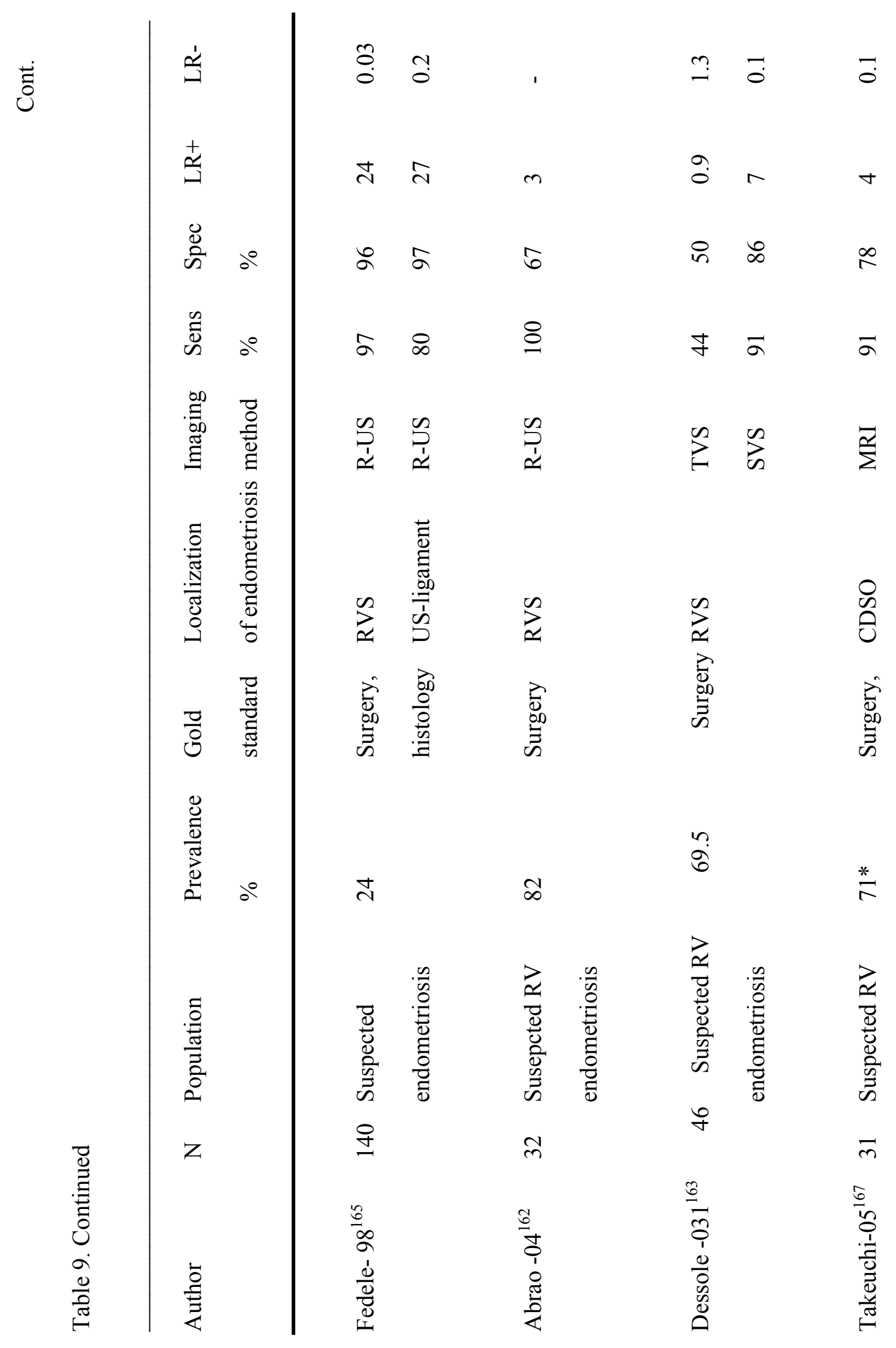




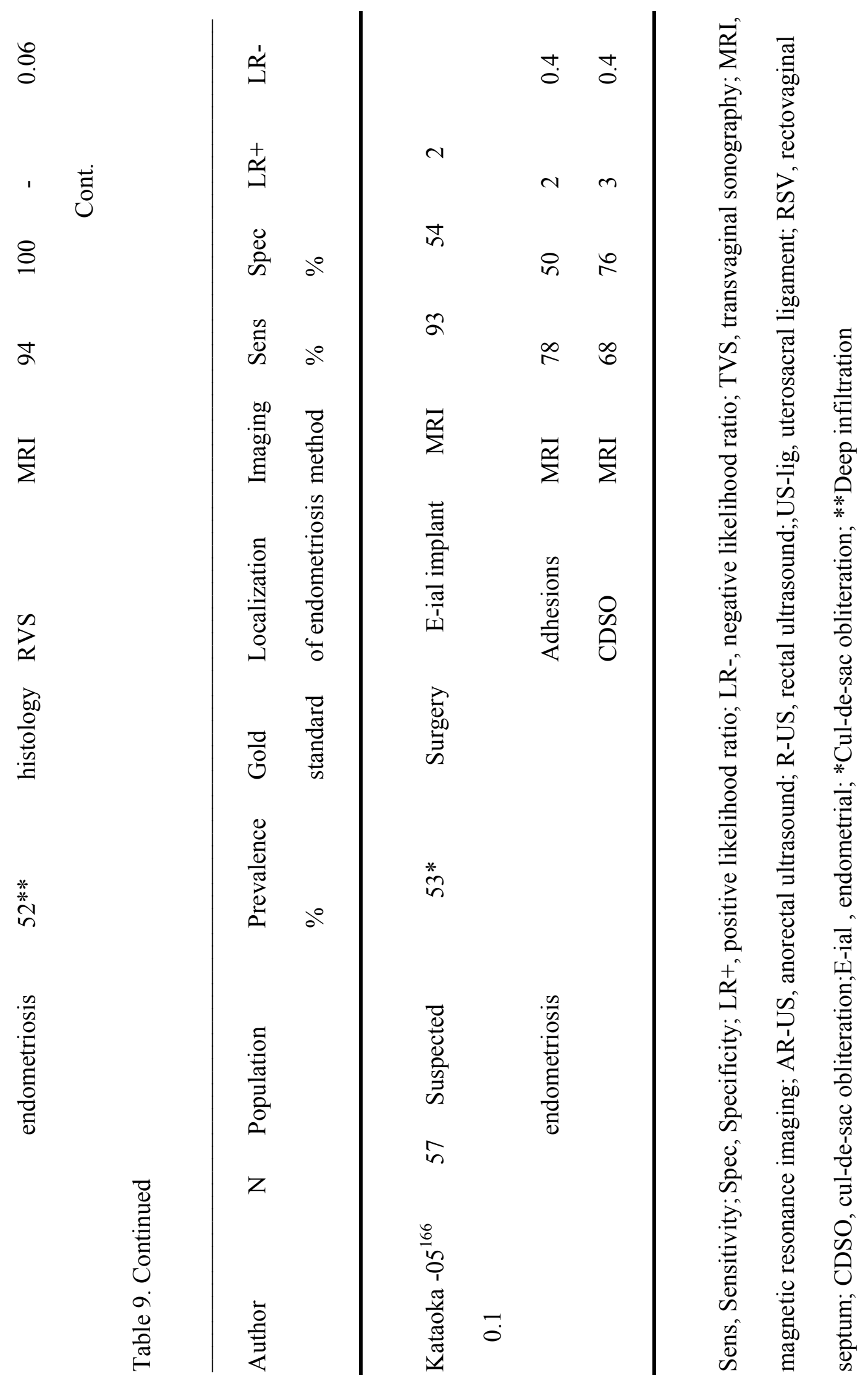

